\title{
Assessment of Hydration Status in Peritoneal Dialysis Patients: Validity, Prognostic Value, Strengths, and Limitations of Available Techniques
}

\author{
Maria-Eleni Alexandrou ${ }^{a} \quad$ Olga Balafa $^{\mathrm{b}} \quad$ Pantelis Sarafidis $^{\mathrm{a}}$ \\ aDepartment of Nephrology, Hippokration Hospital, Aristotle University of Thessaloniki, Thessaloniki, Greece; \\ bepartment of Nephrology, University Hospital of loannina, loannina, Greece
}

\section{Keywords}

Peritoneal dialysis · Volume overload - Inferior vena cava . $\mathrm{N}$-terminal pro-B-type natriuretic peptide $\cdot$ Bioimpedance analysis · Lung ultrasound

\begin{abstract}
Background: The majority of patients undergoing peritoneal dialysis (PD) suffer from volume overload and this overhydration is associated with increased mortality. Thus, optimal assessment of volume status in PD is an issue of paramount importance. Patient symptoms and physical signs are often unreliable indexes of true hydration status. Summary: Over the past decades, a quest for a valid, reproducible, and easily applicable technique to assess hydration status is taking place. Among existing techniques, inferior vena cava diameter measurements with echocardiography and natriuretic peptides such as brain natriuretic peptide and $\mathrm{N}$-terminal pro-B-type natriuretic peptide were not extensively examined in PD populations; while having certain advantages, their interpretation are complicated by the underlying cardiac status and are not widely available. Bioelectrical impedance analysis (BIA) techniques are the most studied tool assessing volume overload in PD. Volume overload assessed with BIA has been associated with technique failure and in-
\end{abstract}

creased mortality in observational studies, but the results of randomized trials on the value of BIA-based strategies to improve volume-related outcomes are contradictory. Lung ultrasound (US) is a recent technique with the ability to identify volume excess in the critical lung area. Preliminary evidence in PD showed that B-lines from lung US correlate with echocardiographic parameters but not with BIA measurements. This review presents the methods currently used to assess fluid status in PD patients and discusses existing data on their validity, applicability, limitations, and associations with intermediate and hard outcomes in this population. Key Message: No method has proved its value as an intervening tool affecting cardiovascular events, technique, and overall survival in PD patients. As BIA and lung US estimate fluid overload in different compartments of the body, they can be complementary tools for volume status assessment.

(c) 2020 S. Karger AG, Basel

\section{Introduction}

Fluid overload is a common complication in CKD, particularly in CKD stage 5 before and after the initiation of renal replacement therapy. Fluid overload increases blood pressure (BP) and cardiac preload and has been as-

\section{KARGER}

(c) 2020 S. Karger AG, Basel

karger@karger.com

www.karger.com/ajn
Olga Balafa

Department of Nephrology, University Hospital of Ioannina

St. Niarchou Ave. 1

GR-45500 Ioannina (Greece)

olgabalafa@gmail.com 
sociated with heart failure, left ventricular hypertrophy, and mortality both in hemodialysis (HD) $[1,2]$ and peritoneal dialysis (PD) populations [3-5]. Thus, one of the main goals of adequate renal replacement therapy in patients with ESRD is to avoid fluid overload and maintain euvolemia.

Assessment of fluid status (i.e., overhydration $[\mathrm{OH}]$, normohydration, and dehydration) was traditionally based on clinical examination including assessment of $\mathrm{BP}$, peripheral edema, lung auscultation, and simple diagnostic tools, for example, chest X-ray. The International Society of Peritoneal Dialysis suggest that "hydration status should be assessed clinically on a regular basis during every follow-up visit and more often if clinically indicated" in PD patients [6]. However, these parameters can rather not reliably guide treatment decisions. A previous cross-sectional study in a HD population showed that pedal edema did not reliably reflect the volume status of the patients [7]. A study in PD patients [8] suggested a strong correlation between pedal edema and hypertension, but there is currently no study showing a direct association between signs of volume overload in clinical examination and body volume status assessed with an objective method.

The clinical need of defining the ideal fluid status is perhaps more urgent in PD as some studies have suggested that PD patients could be more overhydrated than individuals undergoing HD [9]. This review presents the currently used methods to assess fluid status in PD patients and discusses the existing evidence on their validity, applicability, limitations, and associations with intermediate and hard outcomes.

\section{General Principles of Fluid Status Assessment}

The gold-standard methods for fluid status assessment are isotope dilution analysis techniques. Deuterium and tritium dilution are preferred ways to measure total body water (TBW), while bromide chloride and sucrose dilution are used for extracellular volume (ECV) [10]. However, these methods are invasive, expensive, and largely unfeasible in clinical routine. DEXA dual-energy X-ray absorptiometry can provide data about fat, lean soft, and bone tissue mass [11]. DEXA is considered to be superior to other methods for determining body composition in dialysis patients, although hydration can affect the estimation of lean soft tissue mass, and ideally, it should be combined with a trace dilution method $[10,12,13]$. Furthermore, estimation of bone tissue mass by DEXA in
ESRD patients is also problematic, since as a bi-dimensional measurement of "areal" and not "true volumetric" density, it is confounded by the presence of extra-osseous calcium and fails to recognize the histological type of renal osteodystrophy and to predict bone turnover type [14, 15].

Over the years, several bedside methods (ultrasound [US] assessment of inferior vena cava [IVC] diameter, bioimpedance analysis, and lung US) and biomarkers were increasingly used in an effort toward objective fluid status assessment both in HD and PD patients. These techniques have been tested in numerous studies with different aims: (i) as methods to estimate ideal dry weight either cross-sectionally or during longitudinal follow-up, (ii) as predictors of cardiovascular or all-cause mortality, and (iii) less frequently, in intervention studies with soft (achievement of normohydration) or harder end points (change of echocardiac parameters).

It is important to note that the above methods do not assess all body compartments. Fluid can accumulate in different body compartments, that is, intracellular water and extracellular water (ICW and ECW, respectively); the latter can be divided in intravascular and interstitial compartments [16]. Fluid overload in the intravascular compartment of ECW is mostly associated with cardiovascular mortality, while fluid in ICW is directly associated with muscle mass [17]. Bioimpedance techniques can provide estimations of ECV, intracellular volume, and TBW, whereas IVC diameter measurements, biochemical markers (such as brain natriuretic peptide, BNP), and lung US provide information that corresponds to the amount of fluid in the intravascular compartment (Table 1).

\section{IVC Diameter}

Measurement of the diameter of IVC and its decrease on deep inspiration (collapsibility index-CI) by echocardiography is good estimation of right atrium pressure; as pressure increases in the right atrium, this is transmitted to the IVC, resulting in reduced collapse with inspiration and IVC dilatation. IVC diameter $<2.1 \mathrm{~cm}$ that collapses $>50 \%$ with a sniff or inspiration suggests normal RA pressure of $3 \mathrm{~mm} \mathrm{Hg}$ (range, 0-5 $\mathrm{mm} \mathrm{Hg}$ ) [18]. The diameter of the IVC was previously used to assess volume overload in HD patients [19]. In PD populations, the IVC diameter, especially maximal diameter in quiet expiration (IVCe), was previously shown to correlate significantly with cardiothoracic ratio $(r=0.53, p<0.001)$ and plasma 


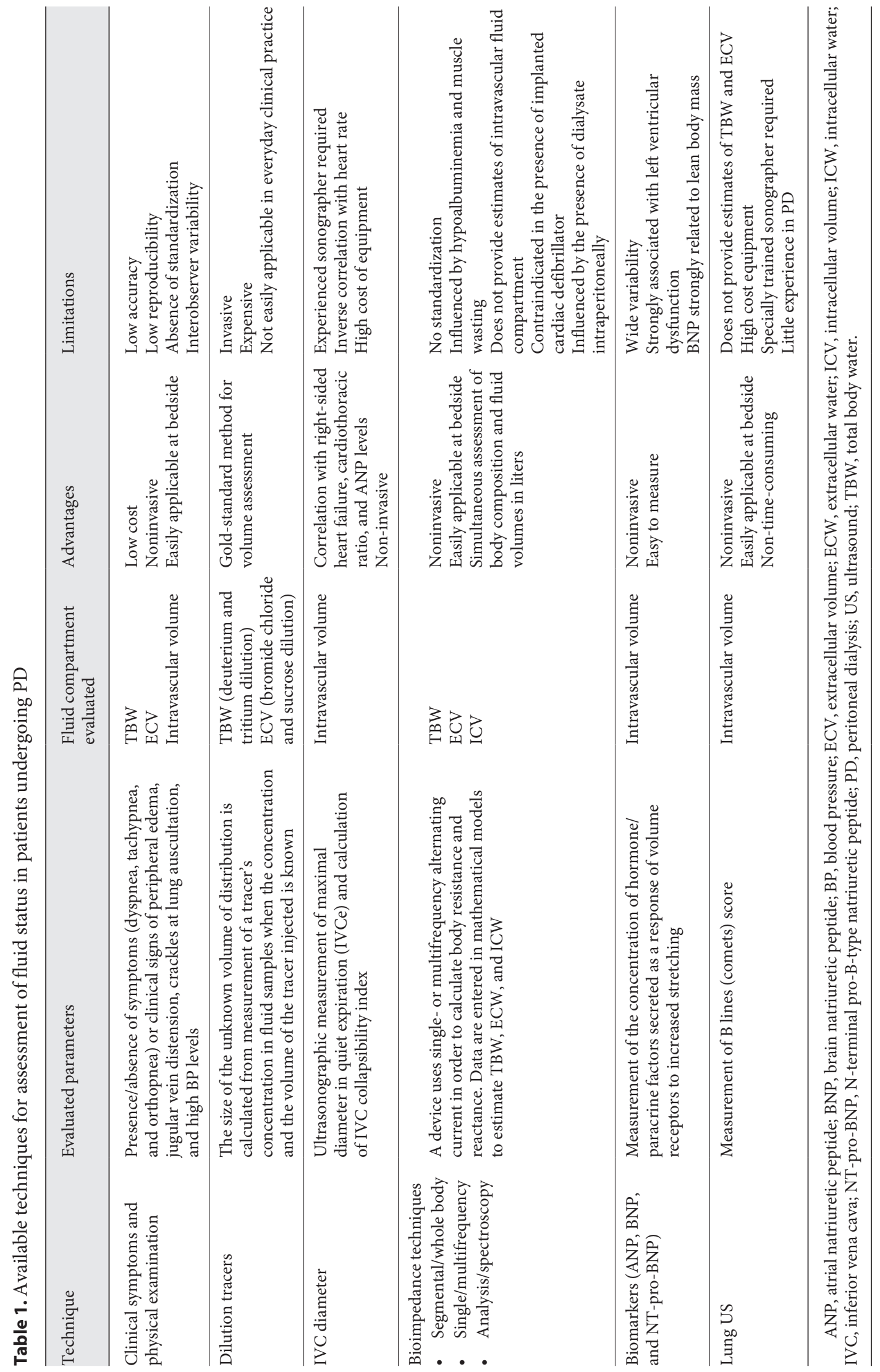


atrial natriuretic peptide (ANP) concentration $(r=0.59$, $p<0.05$ ) [20]. IVC was a useful tool for assessing the fluid status in PD patients and correlated - when compared with bioelectrical impedance analysis (BIA) measurements - moderately with ECW/TBW $(r=0.42 ; p<0.05)$ and ICW/ECW $(r=-0.47 ; p<0.025)$ [21]. It also correlates with left ventricular geometric stratification [22]. However, as of this writing, no study has assessed the validity of IVC diameter for fluid overload assessment, in relation to gold-standard techniques.

Despite the obvious advantages of assessing volume status with IVC, some caveats should kept in mind that (i) there is a wide variation of IVC diameters in healthy individuals, and single measurements are not helpful, (ii) there is a significant, inverse correlation between IVC diameters and heart rate, and the precision of intravascular volume assessment is improved by correcting for the heart rate, and(iii) the presence of tricuspid insufficiency and right-sided cardiac failure leads to unreliable results [23]. Based on these remarks, IVC diameters should be performed and interpreted by an experienced cardiologist. Finally, as discussed above, one should keep in mind that IVC estimates only intravascular (preload) volume and has a rather low reproducibility [24].

\section{Natriuretic Peptides}

Natriuretic peptides, that is, $\mathrm{BNP}, \mathrm{N}$-terminal pro-Btype natriuretic peptide (NT-pro-BNP), and ANP are hormones that are released by ventricular or atrial myocytes in response to the myocyte stretch, such as increased preload or afterload [25]. Both are well-studied biomarkers in heart failure and CKD patients [26], where they mainly increase due to ECV expansion. Apart from the volume overload, BNP is increased with reduced GFR. Although the clearance of both peptides, especially NTpro-BNP, is mainly renal (filtered by the glomerulus and degraded in the proximal tubule [27]), it seems that the severity of structural heart disease defines the levels of the peptides in advanced CKD disease more than renal clearance itself $[28,29]$.

Plasma BNP levels are known to decrease significantly after an HD session, implying that volume overload is related to BNP increase; however, removal during $\mathrm{HD}$ is also part of the equation [30]. In $\mathrm{HD}$ [31] and $\mathrm{PD}$ populations [32], elevated levels of natriuretic peptides are related with increased cardiovascular and overall mortality. Specifically in PD populations, plasma BNP and NT-proBNP levels are elevated [33] and correlate with volume overload [34], while not all peptides are predictive of mortality. A sub-analysis of the ADEquacy of peritoneal dialysis in MEXico study, including 965 PD patients, showed that plasma levels of cardiac natriuretic peptides (NT-pro-BNP, pro-ANP[1-30], pro-ANP[31-67], and pro-ANP [1-98]) are elevated in patients on $\mathrm{PD}$ and correlate with the level of residual renal function (RRF) and systolic BP; however, only NT-pro-BNP was associated with cardiovascular and overall mortality $[35,36]$. A study with PD patients from Korea compared 3 biomarkers (NT-pro-BNP, hsCRP, and cTnT) regarding the prognosis of mortality. The study concluded that NT-pro$\mathrm{BNP}$ is a more significant prognostic factor for cardiovascular mortality than cTnT and hsCRP, whereas hsCRP is associated more closely than NT-pro-BNP and cTnT for all-cause mortality [37]. Currently, there are no studies specifically assessing the validity of natriuretic peptides for assessing fluid status in PD patients against gold-standard techniques. Overall, existing evidence suggests that the above peptides are elevated in PD patients and correlate with echocardiographic parameters of the left ventricle (LV) and, in some cases, mortality. Their elevated levels independently identify a subset of patients at greater risk for death, but they cannot be used to assess volume status [38]. Further, the levels of these peptides may be affected by underlying heart function and are not universally available [24].

\section{BIA Techniques}

\section{Typology}

Bioimpedance analysis is a simple, noninvasive, and by-the-bed method to estimate fluid distribution in body compartments. Table 2 presents the basic assumptions, estimated parameters, advantages, and limitations of the various types of BIA techniques. The basic principle of bioimpedance techniques is that when a low-strength alternating current (usually $50 \mathrm{kHz}$ ) passes through the body, biological tissues react accordingly to the current frequency and the properties of the tissue (called impedance) $[39,40]$. The two basic properties of impedance are resistance and capacitance and the former measures the flow of the electrons through the tissue, the latest refers to how much energy is stored and released in each current alternating cycle. Resistance is proportional to the amount of fluid, while capacitance is proportional to the cell mass. There are mainly four methods of body fluid volume assessment: (a) prediction of TBW with function of singlefrequency $(50 \mathrm{kHz}),(\mathrm{b})$ use of low $(1-5 \mathrm{kHz})$ and high 


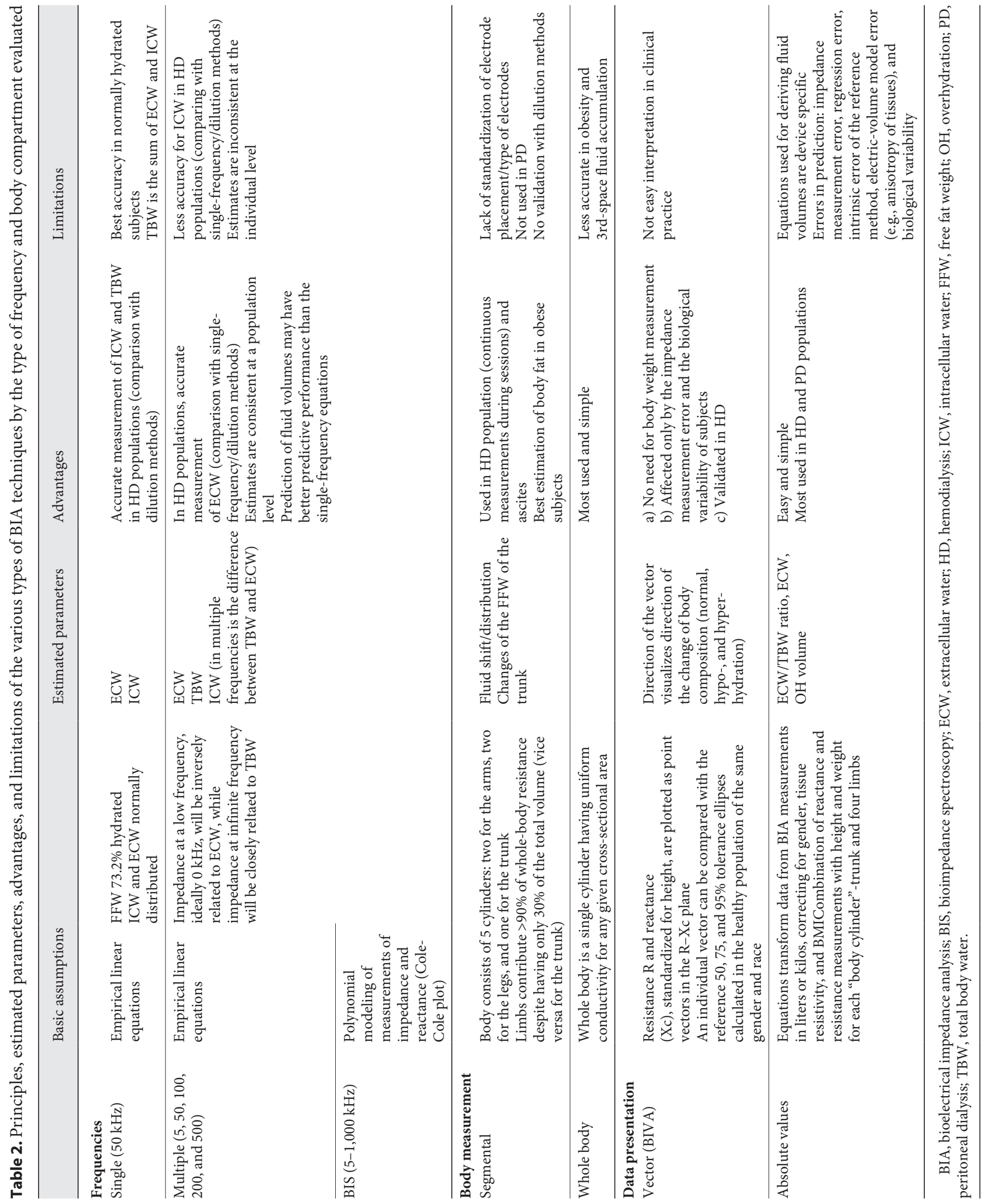


$(100-500 \mathrm{kHz})$ frequencies and (c) bioimpedance spectroscopy (BIS) where a broad band of frequencies (1$1,000 \mathrm{kHz})$ is used (Low-frequency currents $(<5 \mathrm{kHz})$ pass through the ECV (they cannot pass the cell membrane), while high-frequency currents pass though both $\mathrm{ECV}$ and intracellular volume compartments [41]. A variable amount of very low-frequency current, regardless at which frequency the current is introduced, can penetrate the membranes of muscle cells, particularly when the current is parallel to the muscle fiber [42]) and (d) bioimpedance vector measurement (BIVA), where continuous bivariate vector of impedance (resistance and reactance) is evaluated, compared with the deviation from a reference healthy population [43]. These methods can be applied segmentally or as a whole body measurement [44], while the results can be presented as absolute volumes or vector distribution $[45,46]$.

All of the bioimpedance techniques are highly reproducible and validated with gold-standard dilution methods in healthy populations [47]. However, errors in the prediction of volumes may occur mainly due to different devices, lack of standardization and various assumptions, mathematical models and equations used. Thus, a study in athletes which compared a BIS and a single-frequency device showed lack of measurement agreement [48], while even the use of different commercial electrodes could affect the vector estimations due to variability of intrinsic resistance and reactance values [49]. In general, BIS prediction equations could involve 5 different errors: impedance measurement error, regression error (standard error against the reference method), intrinsic error of the reference method, electric-volume model error (e.g., anisotropy of tissues), and biological variability of healthy and diseased subjects. On the contrary, vector analysis (BIVA) seems to engage only mainly measurement error and biological variability, as there is no need for body weight measurement and use of regression equations [43].

In HD populations, single and multifrequency BIA methods have been used [50]; these were either segmental (they measure the change of the resistance in arm, trunk, or calf) or whole body (Table 2). Specifically, continuous intradialytic calf BIS seems a practical method to determine dry weight in HD, based on the relationship between change in fluid volume and change in calf-normalized resistivity or flattening of the curve of change in calf extracellular resistance using a nonlinear model, not influenced by body composition [51,52]. The segmental BIA cannot be used in PD populations since the method presumes rapid volume reduction (as in a HD session) in order to monitor the resistance $[53,54]$. Whole body BIS devices (BCM, Hydra, and InBody) have been used widely in both HD and PD patients for years and offer the ability to perform frequent, rapid, noninvasive assessment of the fluid status [55]. The devices can estimate TBW and ECW, lean tissue mass, and adipose tissue mass based on mathematical models and healthy population data. This is of great interest since there is convincing evidence for an association between volume status, inflammation, and nutritional status [56]. They can also estimate $\mathrm{OH}$ expressed in liters or kilograms, with the index OH/ECW $>15 \%$ being previously proposed as an index of hyperhydration in PD populations [57].

\section{Validation Studies in PD Patients}

In HD patients, BIS measurements seem to perform the best low detection limit when compared with other techniques for volume assessment [58]. However, limited data are available on validation of bioimpedance techniques for assessment of fluid status in PD populations. In a cross-sectional study of $40 \mathrm{PD}$ patients, Bland-Altman analysis showed wide limits of agreement between the gold-standard method of deuterium dilution and multifrequency BIA for TBW (mean difference 2.0 \pm 3.9 $\mathrm{L}$, range -9.2 to $+10.7 \mathrm{~L}$ ) and between bromide dilution and multifrequency BIA for ECV (mean difference -2.7 $\pm 3.9 \mathrm{~L}$, range -9.0 to $+10.1 \mathrm{~L}$ ) [54]. In contrast to the above, in a small study in pediatric PD patients, TBW measured with single-frequency BIA provided a good estimate of TBW assessed with the tracer dilution technique with small divergence of reported values (mean difference: $0.33 \pm 1.44 \mathrm{~L}, 95 \% \mathrm{CI}$ from -0.93 to +0.26 , rootmean-square-error: $1.45 \mathrm{~L}$ ) [59]. With regard to the definition of $\mathrm{OH}$, a cutoff point of relative $\mathrm{OH}([\mathrm{OH} / \mathrm{ECW}]$ $\times 100)>15 \%$ and more recently of $>17.4 \%$ has been recommended by extrapolation of data from HD populations, where hydration status above this value was associated with worse survival in multivariate Cox regression analysis (HR 2.72, 95\% CI 1.6-4.0) [60].

\section{Technical Limitations of BIA Use in PD Patients}

BIA methods may have some particular limitations when used in PD populations. An observational study in $34 \mathrm{PD}$ patients that were evaluated by whole body multifrequency BIS with full and empty abdomen suggested that presence or absence of the dialysate fluid in the peritoneal cavity can have a major influence on volume status assessment. Significant differences were found before and after draining the cavity with regard to the $\mathrm{OH}$ volume $(1.82 \pm 1.73 \mathrm{~L}$ vs. $1.64 \pm 1.68 \mathrm{~L}, p=0.043)$ and relative $\mathrm{OH}$ 
$(8.29 \pm 6.96 \%$ vs. $7.14 \pm 6.79 \%, p=0.017)$ [61]. Based on these findings, it is likely that the ideal BIA measurements should be performed with empty abdomen. However, this is clinically impractical, and most clinicians suggest that the differences in measurements are probably not clinically significant. Measurements with full abdomen made in a standardized way and performed serially can document changes of volume status, which is most important [62].

Hypoalbuminaemia is another issue that can compromise proper BIA use in PD; it is more common and serious in PD patients who have large protein losses though the membrane, especially those that are high transporters or inflamed [63]. The ratio ECW/TBW is affected (increased, due to a decrease in TBW estimation) both by muscle wasting and abnormal tissue hydration. Clinicians should keep in mind that absolute values of BIS measurements are based on algorithms derived from healthy Caucasian populations, whose body composition and fluid distribution is quite different from dialysis patients. For example, TBW estimates from BIA measurements assume a fixed hydration of lean body mass [64], whereas in hypoalbuminemic PD patients, tissue hydration is increased and TBW is underestimated. In a cohort of HD patients, followed over 12 months, BIA measurements were combined with absolute measurement of TBW using dilution tracers. ECW/TBW ratio was significantly related to comorbidity due to reduced TBW, which reflected the muscle wasting associated with disease burden, age, and inflammation as mortality risk increases. The same study found an increasing discrepancy between BIA-derived and isotope-measured TBW as comorbid burden increased [65]. In a cohort of PD patients [66], hypoalbuminemia was an important determinant of tissue $\mathrm{OH}$, which was not associated with an increased plasma volume (measured by dilution methods). Finally, BIA fails to distinguish between intravascular and interstitial ECW excess [67]. For all these reasons, some authors suggested that there is not yet clear evidence that BIA methods have clinical benefits in fluid assessment in PD patients [68].

Observational Studies on the Prevalence of Volume

Overload and Its Association with BP Levels in PD

Patients

In PD populations, the majority of studies using bioimpendance techniques are observational. The largest observational trial was performed in 135 European centers and included 1,054 patients (IPOD-PD study) [69]. The study revealed that the majority (56.4\%) of patients

Volume Status Assessment in Peritoneal Dialysis were moderately and severely overhydrated based on a cutoff level of $>1.1 \mathrm{~L}$. At initiation of $\mathrm{PD}$, the mean $\mathrm{OH}$ volume was $1.9 \pm 2.4 \mathrm{~L}$; however, 1 year later, $\mathrm{OH}$ had decreased at $1.2 \pm 1.8 \mathrm{~L}$ and remained relatively stable between the 2 nd and 3 rd year of follow-up $(1.4 \pm 1.8 \mathrm{~L}$ and $1.4 \pm 1.7 \mathrm{~L}$, respectively). According to a linear-mixed model analysis, age, male gender, and presence of diabetes were associated with fluid overload at 1st month (adjusted difference in relative $\mathrm{OH}$ at 1st month for age: 0.1, $95 \%$ CI $0.0-0.1$ per 1 year of increase; for male gender: 3.4 , 95\% CI 2.1-4.7; for presence of diabetes: 4.8 , 95\% CI 3.36.2) [70]. Of note, BIA techniques showed that PD patients presented with higher ECW content compared with HD patients, while studies with serum biomarkers indicated no differences in their levels between PD and HD $[9,71]$.

Volume overload assessed with BIA techniques has been associated to high BP levels in PD patients. In a cross-sectional study [72], 100 stable CAPD patients were divided into 3 groups according to the BP levels (1st group: normotensive, 2 nd group: medically controlled hypertensive, and 3rd group: uncontrolled hypertensive) and studied comparatively, as well as with 60 healthy controls with BIS. ECV normalized for height was found to be significantly higher in patients with uncontrolled hypertension than in normotensives and was positively correlated with SBP and DBP levels $(r=0.42, p<0.01$ and $r=0.39, p<0.01$ respectively). However, incongruent findings have been reported by a recent observational study from Hong Kong, where 96 patients with an $\mathrm{OH}$ volume of $\geq 2 \mathrm{~L}$ (a cutoff value selected based on their inhouse data) were divided in 2 groups of volume overload (symptomatic and asymptomatic) and followed for 12 weeks according to a standardized protocol for volume reduction. Despite significant changes in weight and $\mathrm{OH}$ volume in both groups, a significant decrease in SBP levels by $10 \mathrm{~mm} \mathrm{Hg}$ was detected only in the asymptomatic group (from $146.9 \pm 20.7$ to $136.9 \pm 19.5 \mathrm{~mm} \mathrm{Hg}, p=$ 0.037 vs. baseline) and not in symptomatic, while no significant correlation between $\mathrm{OH}$ volume and SBP was reported $(r=0.160, p=0.15)$ [73].

Observational Studies on the Association of BIA-

Estimated Volume Overload with Mortality and Other Clinical Outcomes in PD Patients

As shown in Table 3, various observational studies have associated $\mathrm{OH}$ assessed with bioimpendance techniques in PD patients with mortality and other clinical outcomes, such as technique failure, which is hypothesized to be related to a harmful effect of chronic volume 


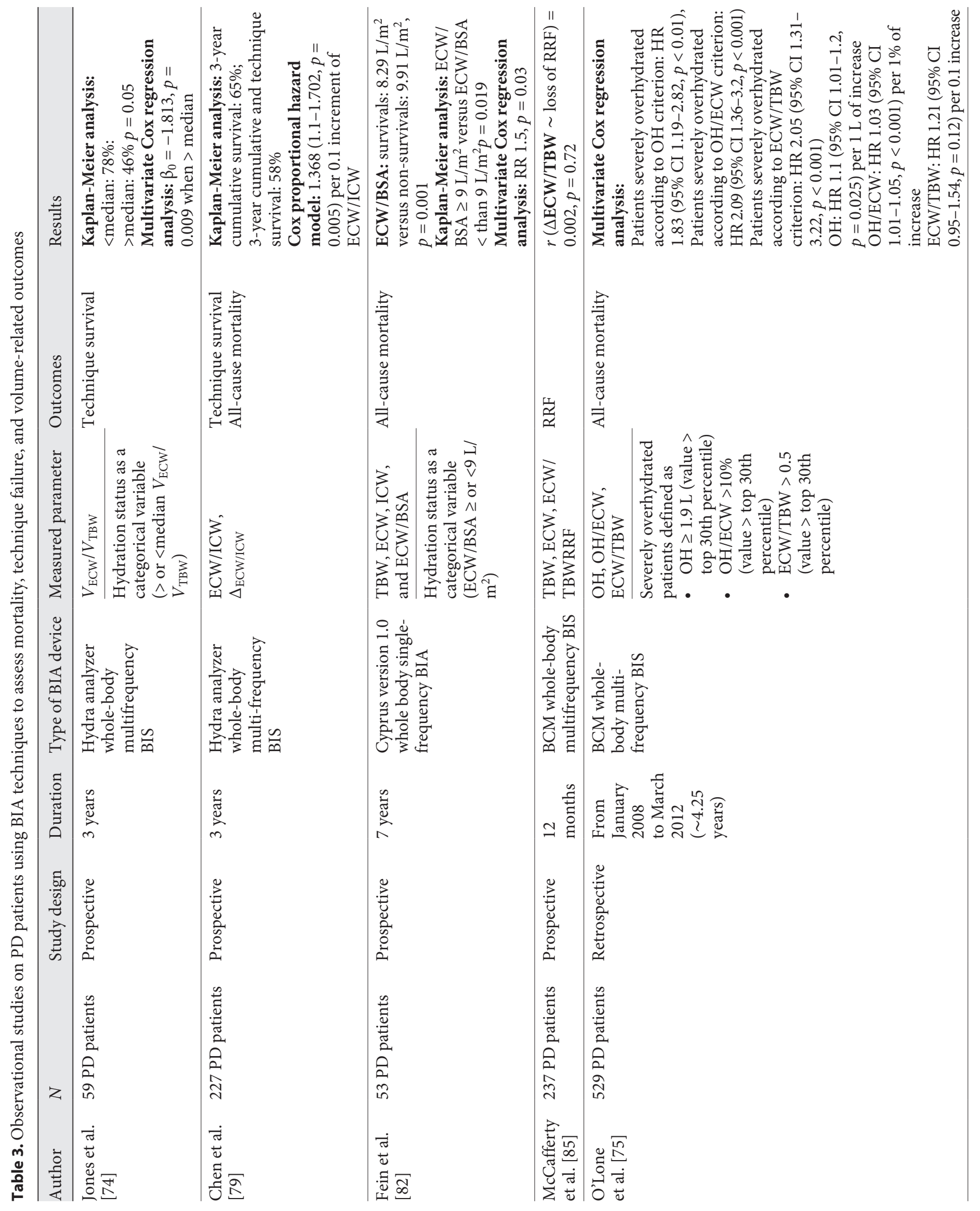




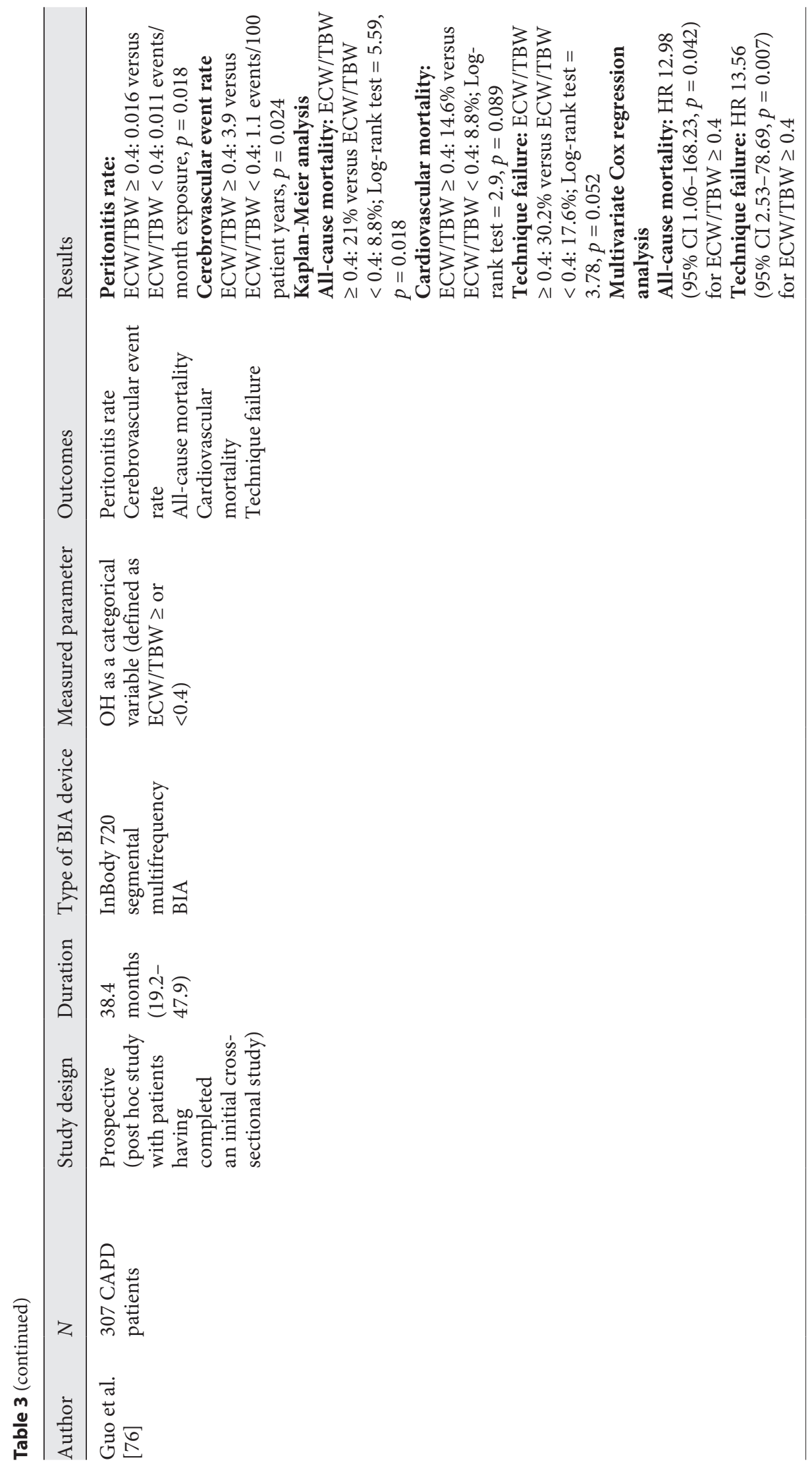




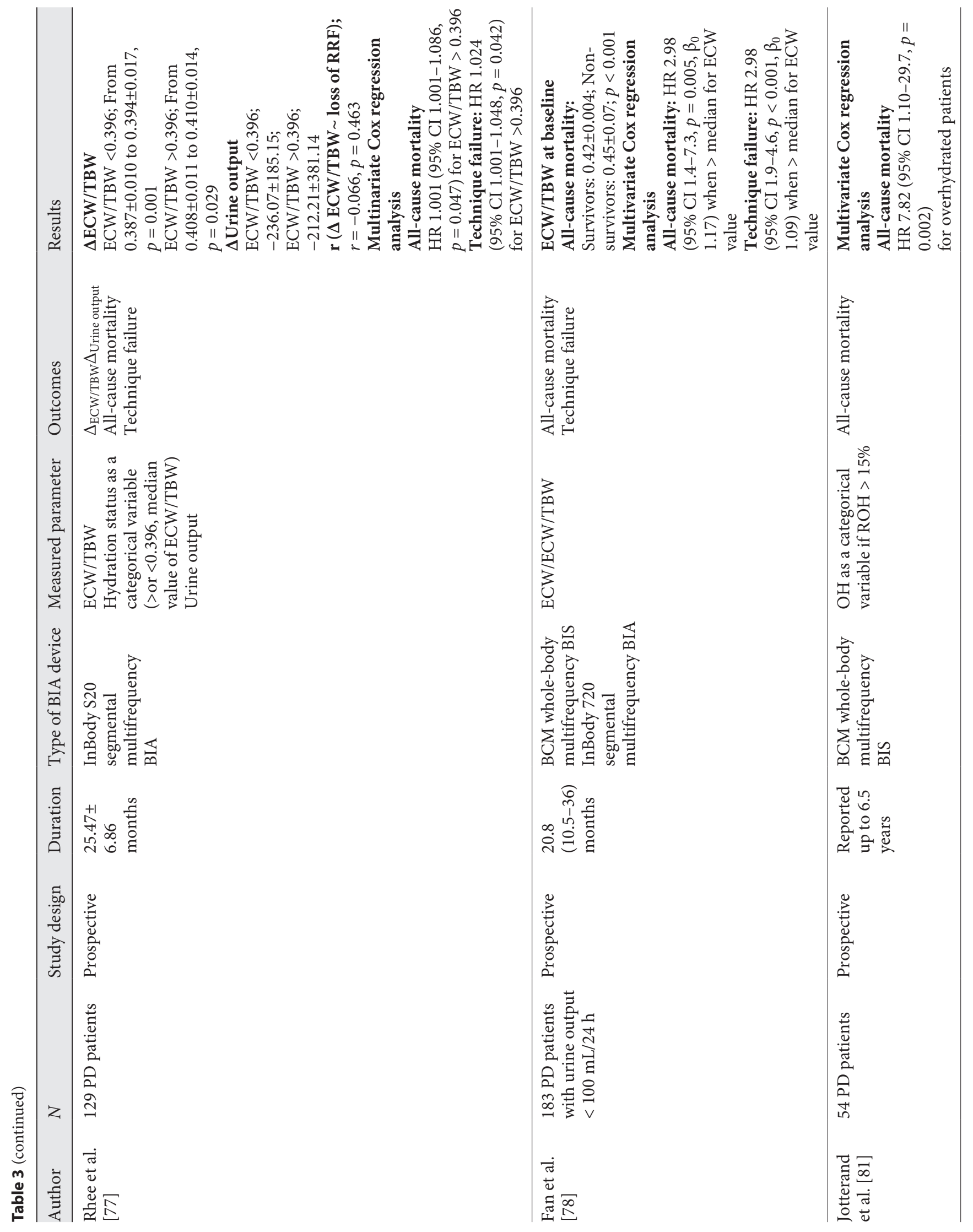




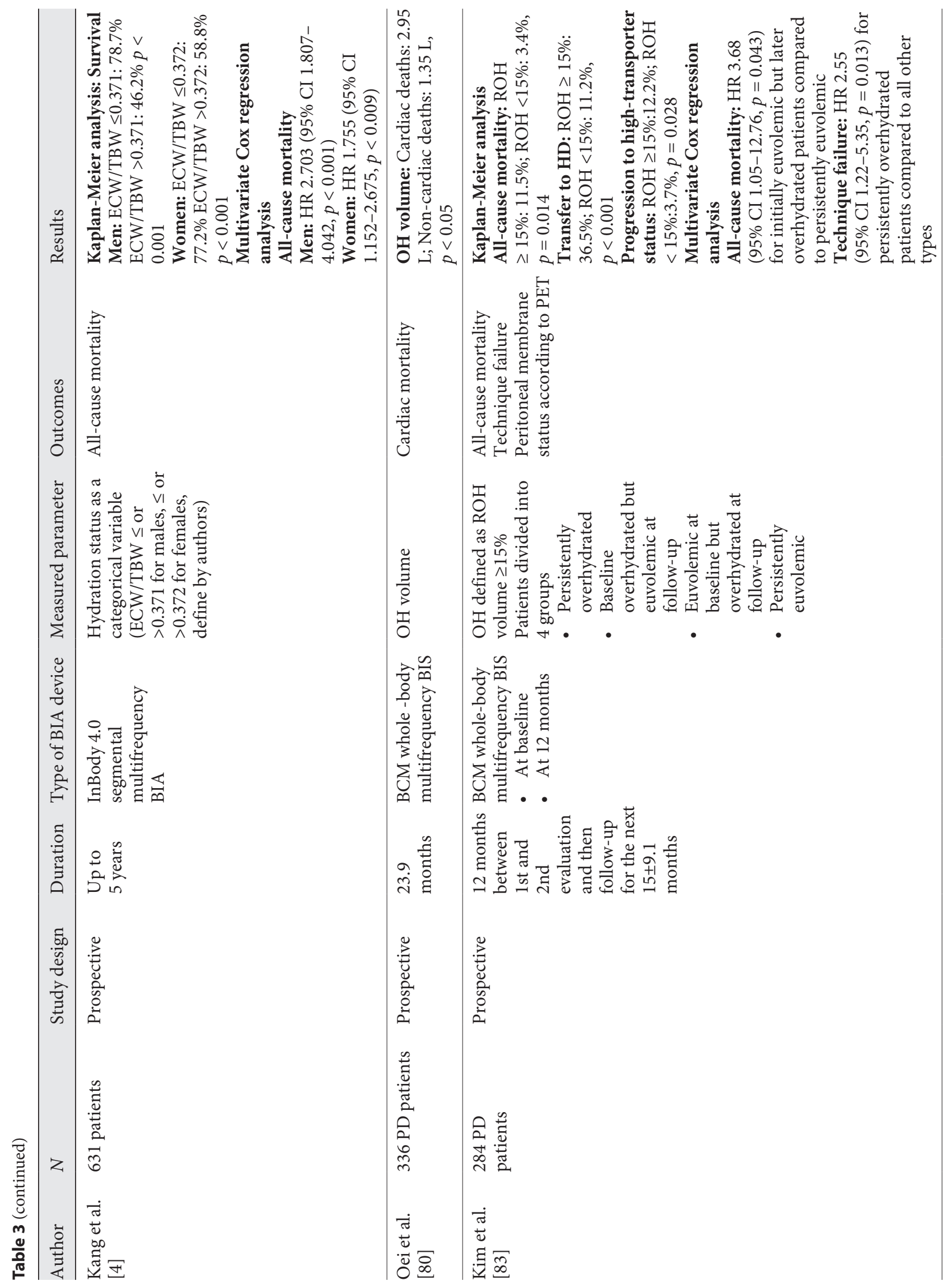

Volume Status Assessment in Peritoneal 


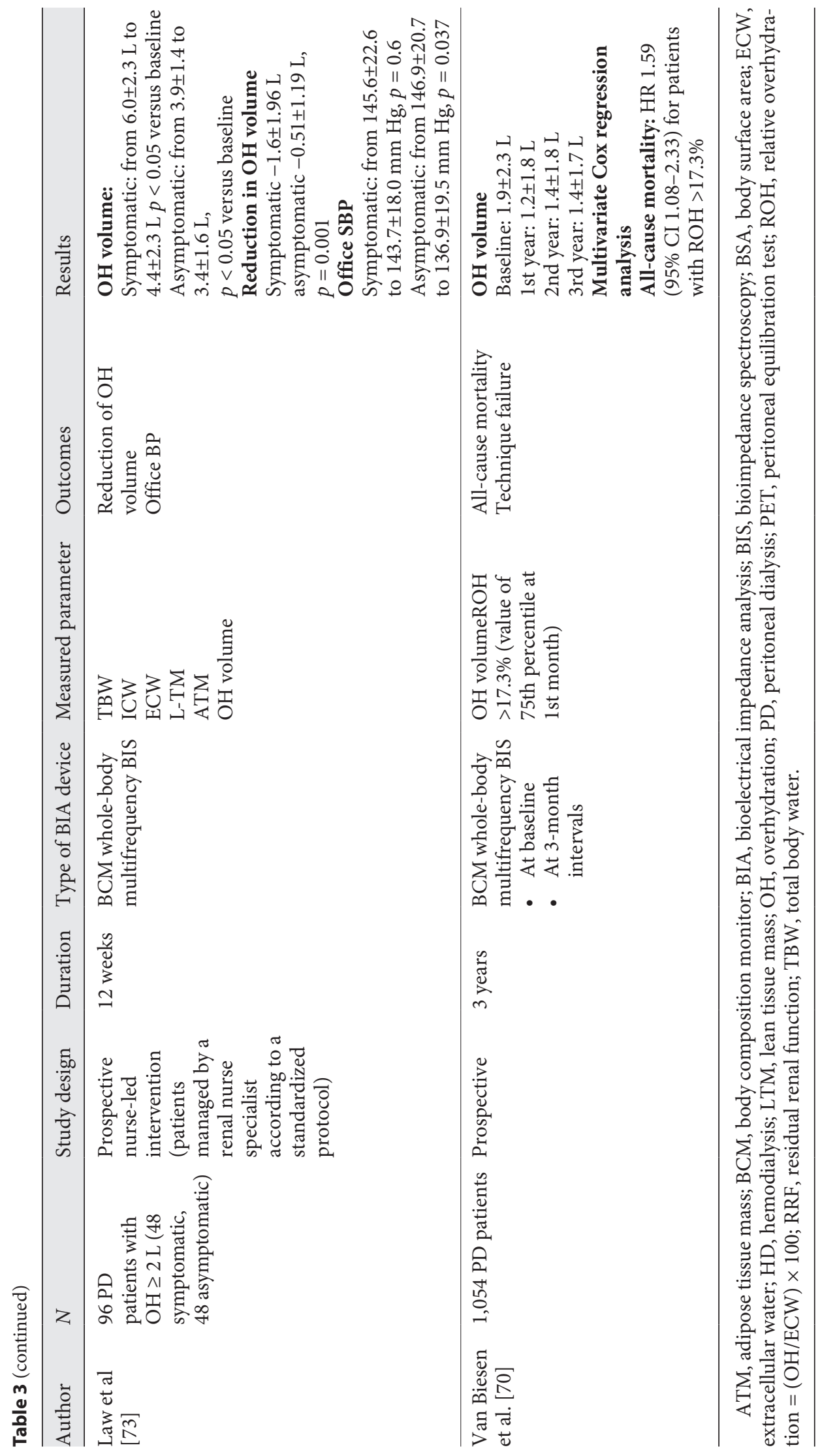


excess on peritoneal membrane characteristics. A study in $59 \mathrm{PD}$ patients with a 3-year follow-up showed that increased $\mathrm{ECW} / \mathrm{TBW}$ is a predictor of worse technique survival $\left(\beta_{0}=-1.813, p=0.009\right.$ for patients with ECW/ TBW values above the median) [74]. Similarly, results of a retrospective study with 529 PD patients from a single UK unit showed that presence of severe $\mathrm{OH}$, defined as values of ECW/TBW being in the upper 30\%, but not the value of ECW/TBW itself is predictive of death (ECW/ TBW as a categorical value HR 2.09, 95\% CI 1.36-3.2 for those in the upper $30 \%$; ECW/TBW as a continuous variable: HR 1.21, 95\% CI 0.95-1.54 per 0.1 increase) [75]. In a Chinese cohort of 307 patients undergoing CAPD, fluid overload (defined as ECW/TBW $\geq 0.4$ ) independently predicted all-cause mortality and technique failure but not cardiovascular deaths (all-cause mortality: HR 12.98, 95\% CI 1.06-168.23; technique failure: HR 13.56, 95\% CI 2.53-78 [76]). In a Korean cohort with 129 PD patients using a similar definition for fluid overload, $\mathrm{OH}$ was a marginally significant predictor of worse survival and technique failure compared to euvolemia (HR 1.001, 95\% CI 1.001-1.086 and HR 1.024, 95\% CI 1.001-1.048, respectively), while hydration status was not correlated with changes in RRF ( $r=-0.066, p=0.463)$ [77]. Results from a cohort from UK with 183 PD patients without RRF showed that patients who were found to be overhydrated at baseline, defined as an ECW value $>$ median, had worse overall and technique survival (HR 2.98, 95\% CI 1.4-7.3 and HR 2.98, 95\% CI 1.9-4.6, respectively [78]). In another Korean cohort with 631 incident PD patients, analysis of data undertaken according to gender showed that fluid overload was associated with higher mortality in men than women (HR 2.703, 95\% CI 1.807-4.042 and HR $1.755,95 \%$ CI 1.152-2.675, respectively [4]). The ECW/ ICW index has also been shown to be an independent predictor of mortality in a prospective study with incident PD patients where mortality risk was increased by $37 \%$ for every increment in the ECW/ICW value by 0.1 (RR 1.368, 95\% CI 1.1-1.702) [79]. Two more prospective studies showed the association of $\mathrm{OH}$ with cardiac deaths (2.95 vs. $1.35 \mathrm{~L}, p<0.05$ ) [80] and all-cause mortality (HR 7.82, 95\% CI 1.10-29.7, $p=0.002$ for overhydrated patients) [81].

In the study with the longest to-date follow-up (7 years) [82], mortality risk increased by $50 \%$ for every liter of increase of the ECW normalized for body surface area (RR 1.5, $p=0.03$ ). In IPOD-PD, the largest to-date cohort with 1,054 incident PD patients and a 3-year follow-up [70], fluid overload defined as a relative $\mathrm{OH}>17.3 \%$ (value of the 75th percentile at 1st month) was independent-

Volume Status Assessment in Peritoneal Dialysis ly associated with a 1.59-fold higher risk of death (HR $1.59,95 \%$ CI 1.08-2.33). In a study that examined longitudinal changes in fluid status and their association with long-term outcomes, 284 prevalent PD patients were evaluated with a BIS device at baseline and at 12 months and were followed-up for another 15 months. Fluid overload was defined as a relative $\mathrm{OH} \geq 15 \%$, and patients were divided into 4 categories according to these 2 test results: (a) chronically overhydrated, (b) initially overhydrated but later euvolemic, (c) initially euvolemic but later overhydrated, and (d) chronically euvolemic. Persistently overhydrated patients had higher mortality rates than all other types ( 11.5 vs. $3.4 \%, p=0.014$ ), were more likely to progress to high transporter status (12.2 vs. 3.7\%, $p=0.028$ ), and to be transferred to HD (36.5 vs. $11.2 \%$, $p<0.001)$. Chronic exposure to fluid overload independently predicted death (HR 3.68, 95\% CI 1.05-12.76) and technique failure (HR 2.55, 95\% CI 1.22-5.35), while subgroup analysis revealed that no deaths were reported in those having become euvolemic [83]. A meta-analysis where data from 5 of the aforementioned studies were analyzed [84] showed a significant association between relative $\mathrm{OH}$ and all-cause mortality. More specifically, a relative $\mathrm{OH}>10 \%$ was associated with a 2.1 -fold increase (RR 2.09, 95\% CI 1.36-3.20) and a relative $\mathrm{OH}>15 \%$ with a 7.8-fold increase (RR 7.82, 95\% CI 1.1-29.7) in mortality. Notably, the ECW/TBW ratio was not found to be associated with a higher risk of death (pooled RR 1.08, 95\% CI 0.96-3.36). Concerning other clinically important outcomes, hydration status assessed with multifrequency BIS could not predict decline in RRF in a cohort of 237 patients with baseline and serial measurements during 12 months where no correlation was detected between changes in ECW/TBW and loss of RRF ( $r=0.02$, $p=0.72)[85]$.

\section{Interventional Studies Using BIA Techniques for}

Volume Estimation in PD Patients

As of this writing, very few interventional studies have been undertaken in PD patients aiming to optimize volume control and adjust dry weight using bioimpendance techniques (Table 4). In an open-label randomized controlled trial (RCT) with 160 participants under CAPD, use of BIS period resulted in better volume control and a significant decrease in mean SBP/DBP during 12 weeks compared to conventional assessment based on clinical examination $(\mathrm{OH}$ volume: $1.72 \pm 1.51 \mathrm{~L}$ vs. $2.52 \pm 1.83$; SBP: $132.99 \pm 19.47$ vs. $139.07 \pm 22.4, p<0.05$ for both comparisons) [86]. In a secondary analysis of a multicenter RCT with data from repeated BIS measurements 


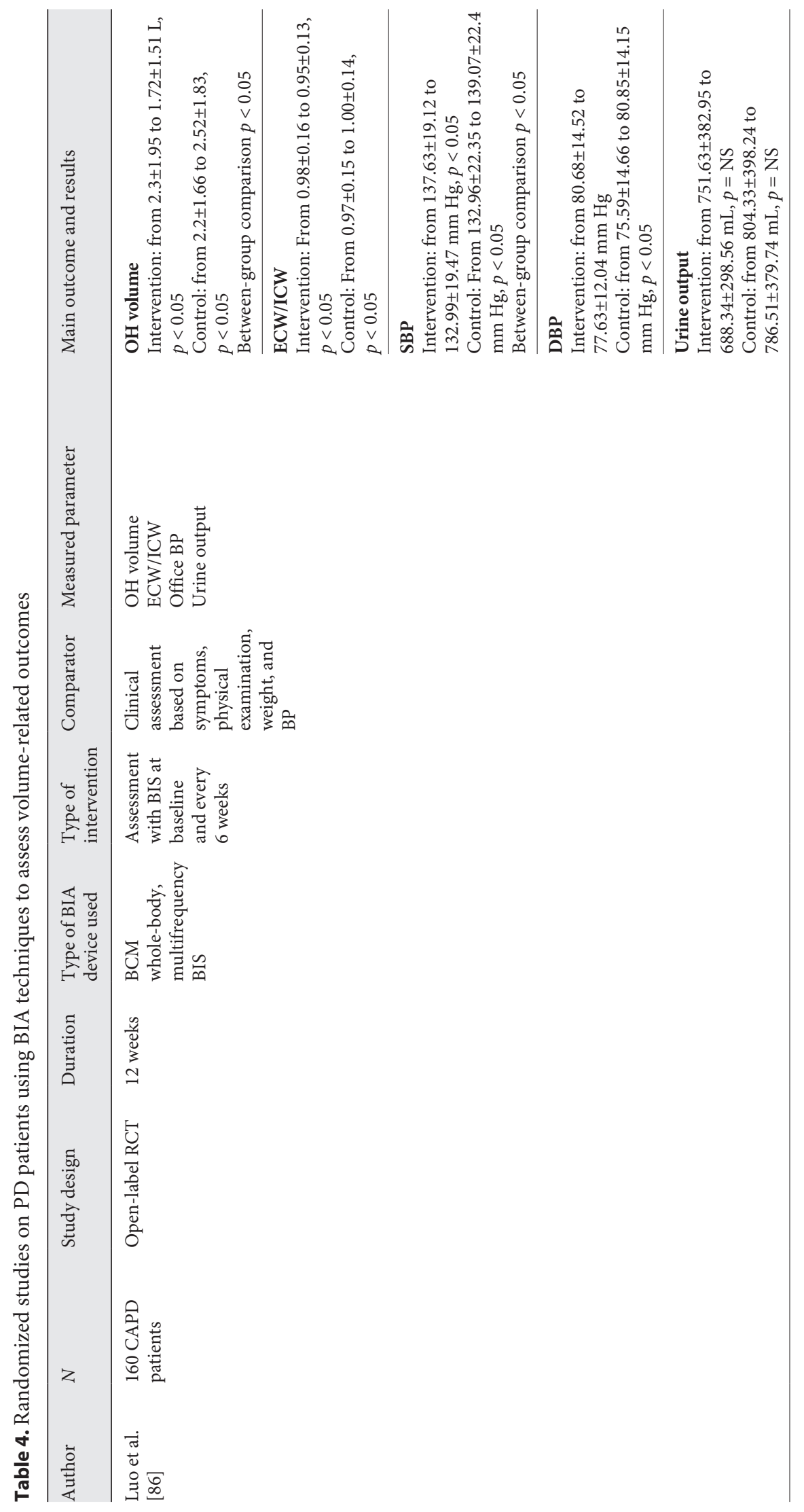




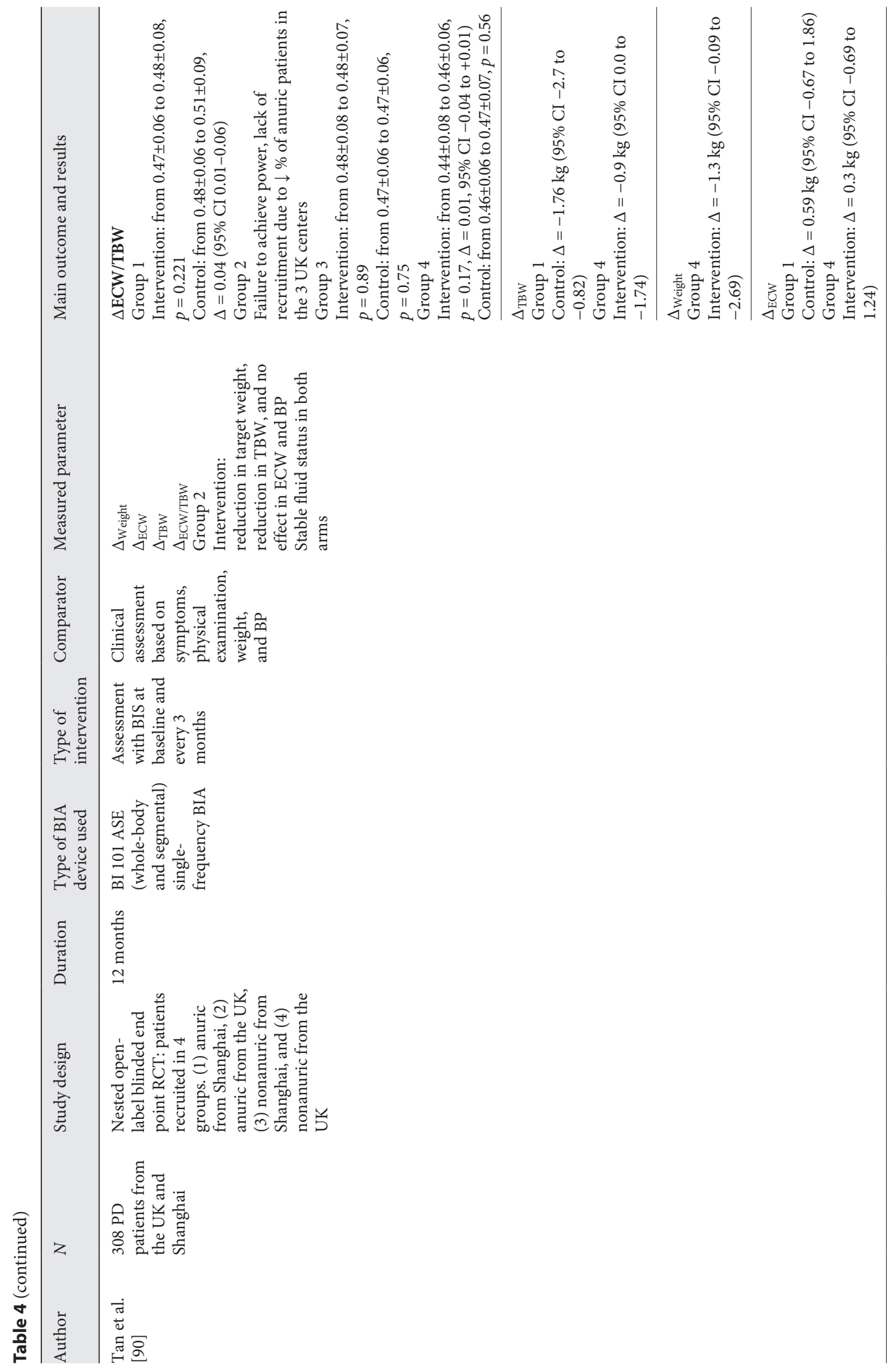




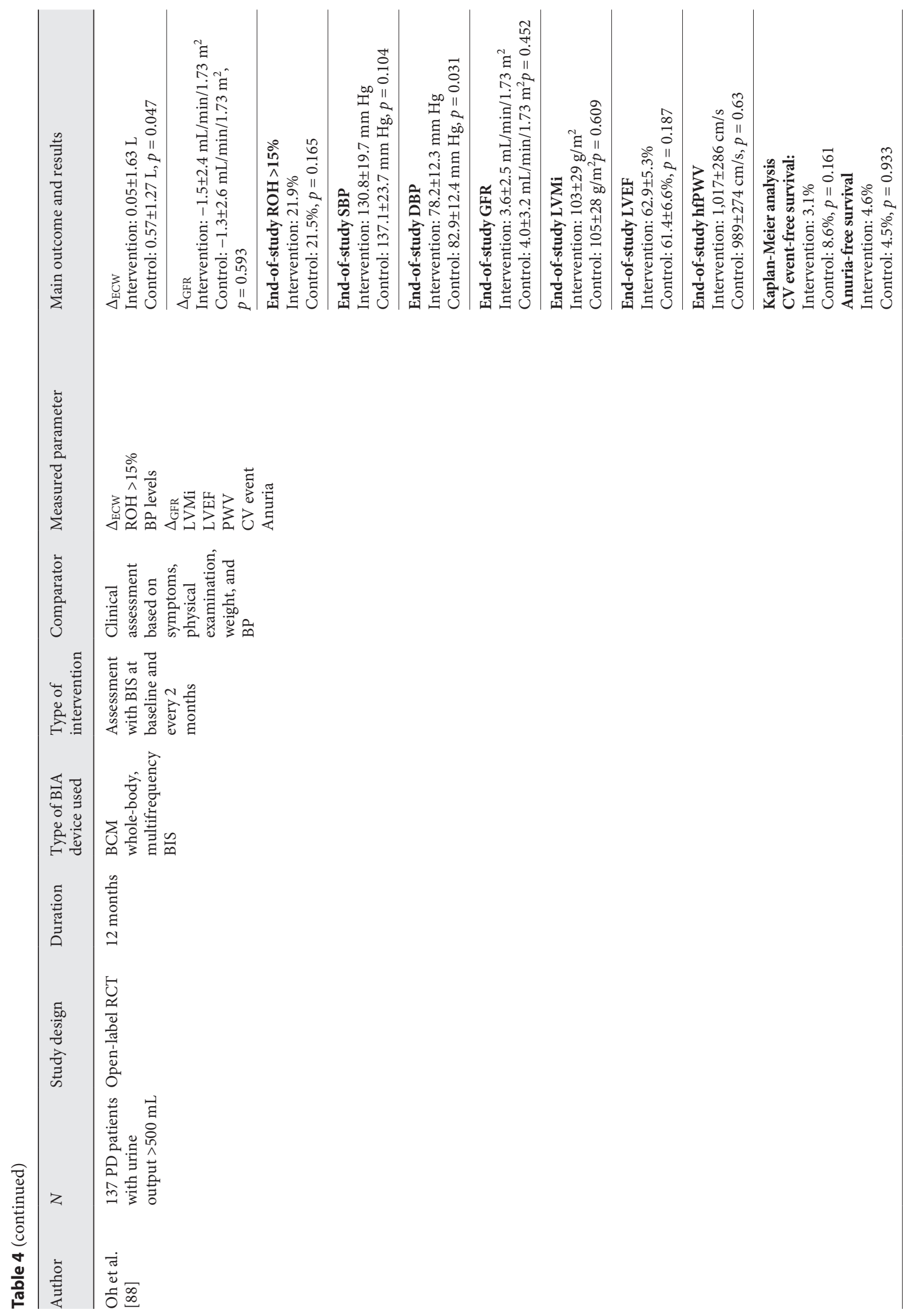




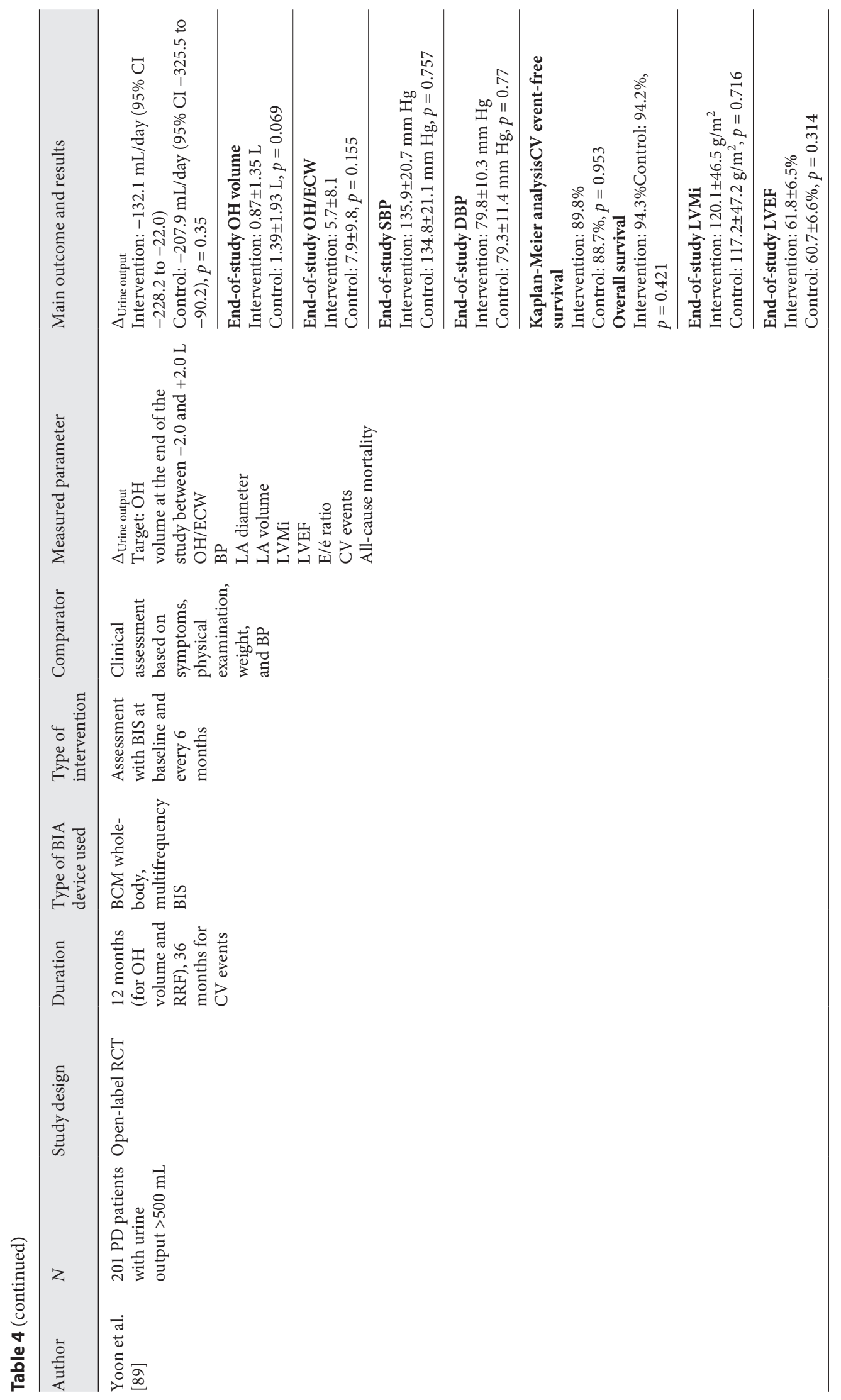




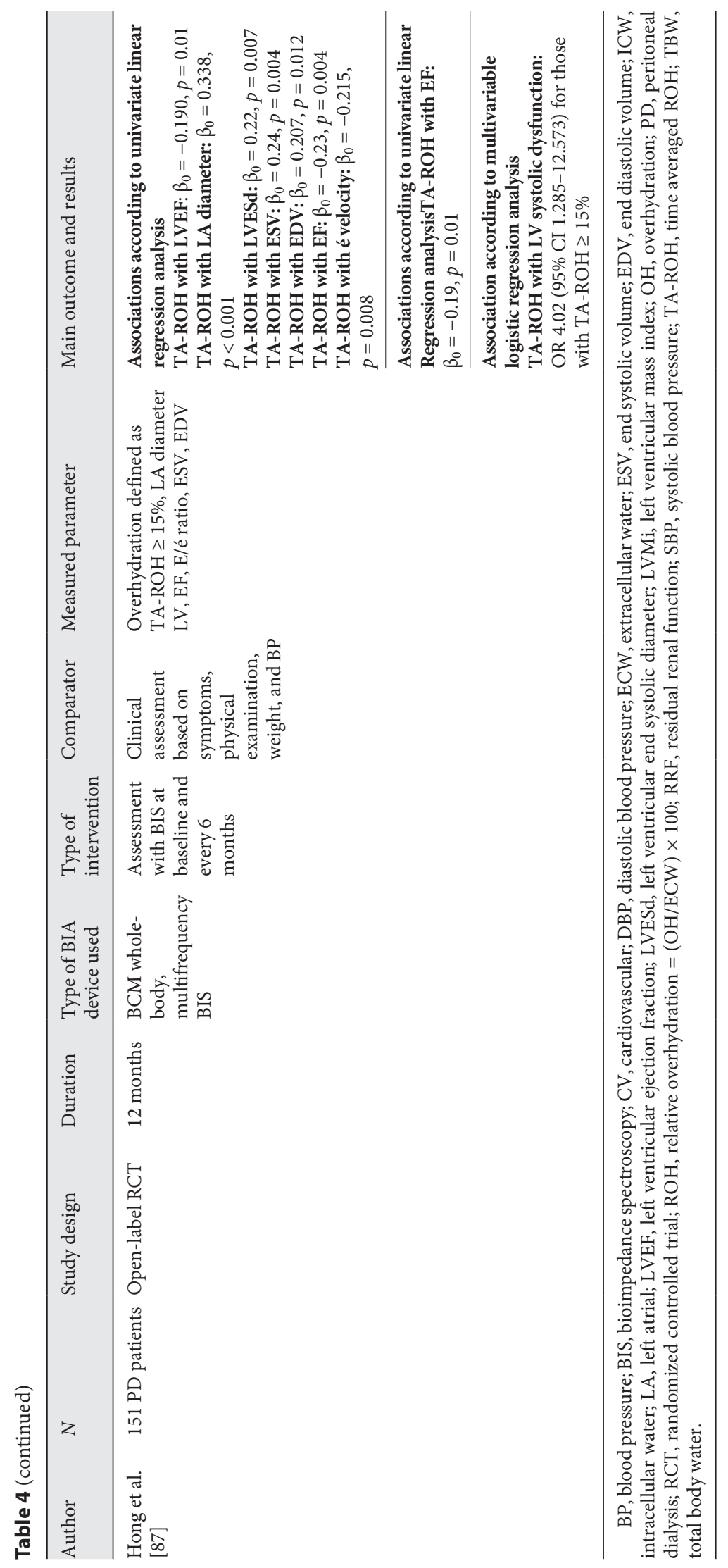


Fig. 1. Principle of lung US technique and ultrasonographic appearance of B lines in a patient with normal (left) and increased (right) LW content. LW, lung water; US, ultrasound.

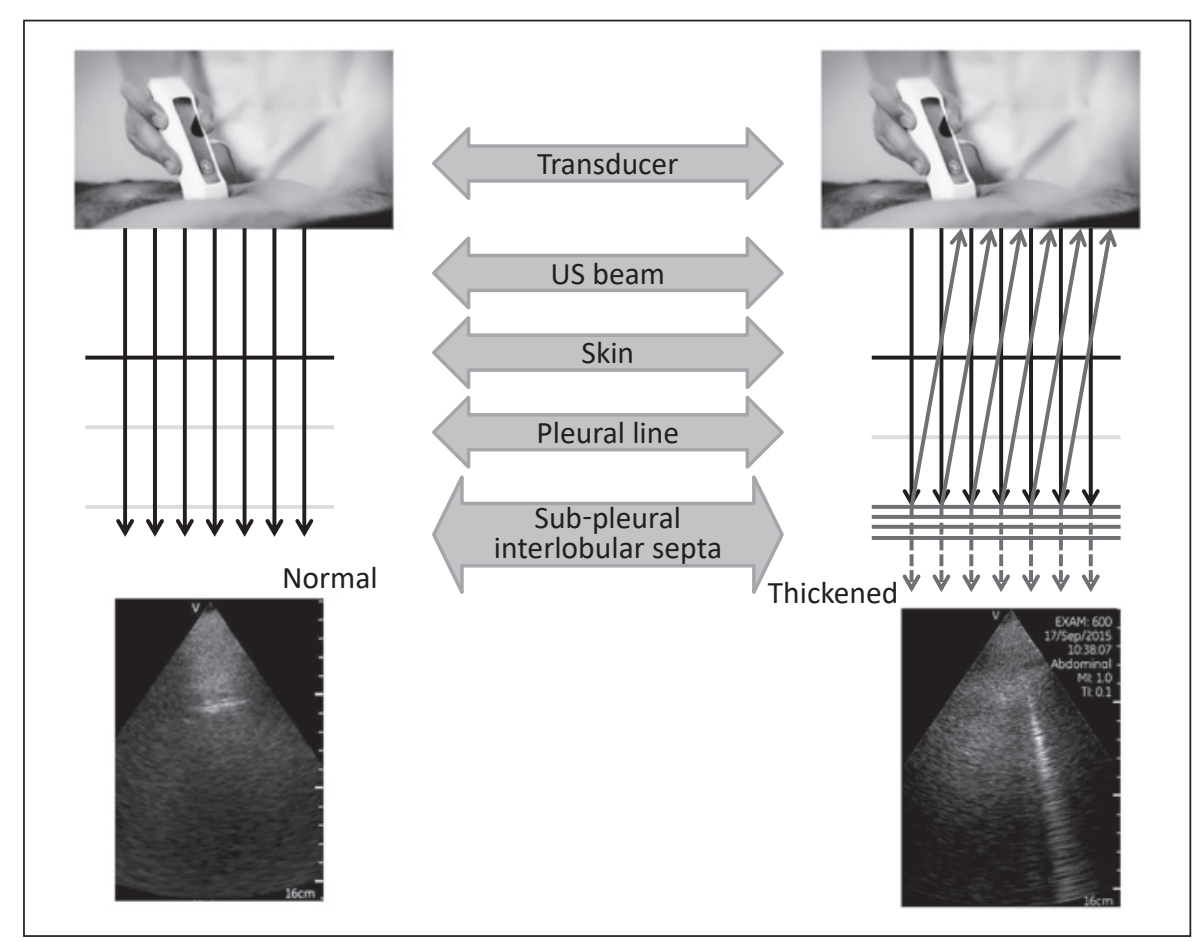

in $151 \mathrm{PD}$ patients, chronic fluid overload, expressed as time-averaged relative $\mathrm{OH} \geq 15 \%$, independently predicted LV dysfunction (OR 4.02, 95\% CI 1.285-12.573) at 12 months. Echocardiographic parameters, including left atrial diameter, end-systolic volume, and end-diastolic volume significantly decreased only in patients with timeaveraged euvolemia $(p=0.014, p<0.001$ and $p<0.001$, respectively) [87].

In contrast to the above, in the COMPASS study, a multicenter RCT with 137 Korean PD patients with urine output $>500 \mathrm{~mL}$, BIS-guided fluid management did not result in longer RRF preservation ( $\Delta$ GFR: $-1.5 \pm 2.4$ vs. $-1.3 \pm 2.6$ $\mathrm{mL} / \mathrm{min} / 1.73 \mathrm{~m}^{2}, p=0.593$ ), the study's primary outcome, nor in better volume control (relative $\mathrm{OH}>15 \%$ : 21.9 vs. $21.5 \% p=0.165$ ) or significant differences in SBP levels (130.8 \pm 19.7 vs. $137.1 \pm 23.7 \mathrm{~mm} \mathrm{Hg}, p=0.104)$, in $\mathrm{LV}$ mass index (103 \pm 29 vs. $\left.105 \pm 28 \mathrm{~g} / \mathrm{m}^{2}, p=0.609\right)$ or in heartfemoral PWV $(1,017 \pm 286$ vs. $989 \pm 274 \mathrm{~cm} / \mathrm{s}, p=0.63)$ compared to conventional clinical assessment after 12 months. Moreover, no added benefit was demonstrated with regard to cardiovascular event-free or anuria eventfree survival between the 2 methods (log-rank $p 0.161$ and 0.933 , respectively) [88]. Similarly, results of another Korean RCT showed that BIS-guided fluid management had no effect on RRF, BP levels, echocardiographic parameters, and CV event rates [89]. In another RCT, 308 PD patients were recruited in 4 groups, according to their country of

Volume Status Assessment in Peritoneal Dialysis origin (UK or China) and status of RRF (anuric or nonanuric) to account for different therapeutic options available and anthropometric characteristics, as well as the effect of remaining kidney function. Patients in all groups were randomized to undergo BIA-guided assessment every 3 months and additionally at clinician's discretion (interventional arm), through 2-dimensional plotting of resistance and reactance data using vector analysis, or clinical assessment (control arm) for a total 12 months. There was a significant effect of BIA-guided interventions in UK nonanuric patients leading to a significant decrease in weight by $-1.3 \mathrm{~kg}$ ( $95 \% \mathrm{CI}-0.09$ to -2.69$)$; in Chinese anuric patients, body composition remained stable in the intervention arm, whereas in the control arm, a significant increase in ECW and a parallel decrease of TBW were noted, leading to an increase of ECW/TBW ratio by 0.04 (09\% CI 0.010.06). However, an increase in the ECW/TBW ratio was noted in all anuric patients at 12 months, regardless of the randomization, probably reflecting loss in lean tissue. In addition to the above, no significant effect of BIA-guided decisions was noted on BP levels [90]. Overall, results of intervention studies in PD patients using BIA are rather less promising than similar studies in HD populations, where strict volume control guided by BIS was associated in some cases with improved left ventricular mass index, BP control PWV, and even mortality [91-93]. It is not yet known if this is a chance effect that can be attributed to small number of 
Table 5. Observational studies on PD patients using lung US to assess volume-related outcomes

\begin{tabular}{|c|c|c|c|c|c|}
\hline Author & $N$ & Study design & Type of device used & $\begin{array}{l}\text { Measured } \\
\text { parameter }\end{array}$ & Main outcome and results \\
\hline \multirow[t]{3}{*}{$\begin{array}{l}\text { Panuccio et al. } \\
\text { [106] }\end{array}$} & \multirow{3}{*}{$\begin{array}{l}88 \text { PD patients } \\
\text { (61 patients } \\
\text { underwent } \\
\text { echocardiography) }\end{array}$} & \multirow[t]{3}{*}{$\begin{array}{l}\text { Cross- } \\
\text { sectional }\end{array}$} & \multirow{3}{*}{$\begin{array}{l}\text { 3.0-MHz Toshiba } \\
\text { NemioXG } \\
\text { echocardiography } \\
\text { probe \& BIA } 101 \\
\text { BIVA, whole-body } \\
\text { single-frequency BIA }\end{array}$} & \multirow{3}{*}{$\begin{array}{l}\text { B lines } \\
\text { LVEF } \\
\text { LA volume } \\
\text { SBP } \\
\text { NYHA class } \\
\text { Edema } \\
\text { Urine output }\end{array}$} & $\begin{array}{l}\text { Multiple regression analysis for score } \\
\text { of lung comets }\end{array}$ \\
\hline & & & & & $\begin{array}{l}\text { For the total population } \\
\text { NYHA class: } \beta=0.31, p=0.006 \\
\text { Residual diuresis: } \beta=0.3, p=0.006 \\
\text { SBP: } \beta=-0.16, p=0.12 \\
\text { Edema: NYHA class: } \beta=-0.11, p=0.31\end{array}$ \\
\hline & & & & & $\begin{array}{l}\text { For patients that underwent } \\
\text { echocardiography } \\
\text { EF: } \beta=-0.36, p=0.007 \\
\text { LA volume: } \beta=0.29, p=0.05 \\
\text { NYHA class: } \beta=0.07, p=0.64 \\
\text { Residual diuresis: } \beta=0.23, p=0.09 \\
\text { SBP: } \beta=-0.16, p=0.22 \\
\text { Edema: } \beta=-0.23, p=0.06 \\
\text { NYHA class: } \beta=-0.11, p=0.31\end{array}$ \\
\hline $\begin{array}{l}\text { Paudel et al. } \\
\text { [107] }\end{array}$ & 27 PD patients & $\begin{array}{l}\text { Cross- } \\
\text { sectional }\end{array}$ & $\begin{array}{l}3.0 \mathrm{MHz} \\
\text { echocardiography } \\
\text { probe \& BCM whole- } \\
\text { body multifrequency } \\
\text { BIS }\end{array}$ & $\begin{array}{l}\text { B lines } \\
\text { OH volume } \\
\text { BP } \\
\text { NT-pro-BNP }\end{array}$ & $\begin{array}{l}\text { Spearman's correlation } \\
r(\mathrm{~B} \text { lines } \sim \mathrm{NT} \text {-pro-BNP })=0.65, \\
p<0.0005 \\
r(\mathrm{OH} \text { volume } \sim \mathrm{NT} \text {-pro-BNP })=0.47, \\
p<0.02 \\
r(\mathrm{OH} \text { volume } \sim \mathrm{B} \text { lines })=0.31, p=0.12\end{array}$ \\
\hline
\end{tabular}

BIA, bioelectrical impedance analysis; BIS, bioimpedance spectroscopy; BP, blood pressure; LA, left atrial; NT-pro-BNP, N-terminal pro-B-type natriuretic peptide; NYHA, New York Heart Association; OH, overhydration; PD, peritoneal dialysis; SBP, systolic blood pressure; US, ultrasound.

studies or small samples or a real difference between PD and HD patients, which could be attributed to reasons such as less frequent adjustment of dry weight in PD or strictly calculated ultrafiltration prescription in HD.

\section{Lung US}

Lung US is an easy and low-cost technique which can be easily applied by nephrologists at the bedside by using a simple US machine [94]. The technique is based on the fact that when lung congestion is present, the US beam is reflected by thickened interlobular septa, generating hyperechoic artifacts between edematous septa and the overlying pleura (the so-called lung comets, considered as a US equivalent of B-lines detected in chest X-rays) (Fig. 1) [95]. The sum number of these lung comets is associated with left ventricular filling pressure, left atrial volume, pulmonary artery pressure, E/é ratio (an index of diastolic function) and the ejection fraction in patients [96]. The power of the method lies in its capacity detecting clinically asymptomatic pulmonary congestion, which is the most early and important determinator of volume overload [97]. It should be mentioned that lung comets do not have specificity only for detecting sole fluid overload, as they also exist in other types of lung disease such as interstitial pulmonary fibrosis or acute respiratory distress syndrome [98].

The feasibility of this technique has been examined in a study including $75 \mathrm{HD}$ patients [99], where lung US revealed moderate to severe lung congestion in $63 \%$ of patients before the dialysis session, most of which were fully asymptomatic. The number of US B lines was not associated with the hydration status evaluated with bioimpedance analysis, but it was significantly associated with LV mass, left ventricular ejection fraction, left atrial volume and pulmonary pressure, and New York Heart Association (NYHA) functional class. In a cross-sectional analysis of baseline data from the ongoing Lung Water by Ultra-Sound Guided Treatment to Prevent Death and Cardiovascular Complications in High Risk ESRD Pa- 
tients with Cardiomyopathy Trial, lung B lines were compared with the presence of crackles and edema in clinical examination as markers of lung congestion [100]. Crackles and edema proved to poorly reflect the presence of lung water as detected by the lung US. Studies that examined the association between the number of B-lines and BIS parameters showed contradictory results; some showed no association, whereas others showed modest correlations $[99,101,102]$. Of note, in prospective cohort study of Zoccali et al. [103], they showed that the number of lung comets can be a strong, independent predictor of mortality and cardiac events in HD patients. Moreover, a recent randomized sub-study of the ongoing Lung Water by Ultra Sound Guided Treatment to Prevent Death and Cardiovascular Complications in High Risk ESRD Patients with Cardiomyopathy Trial compared the effect of gradual dry-weight reduction with a lung US-guided strategy and standard-of-care approach on ambulatory BP in 71 hypertensive HD patients and showed significant reductions of $6.6 / 3.8 \mathrm{~mm} \mathrm{Hg}$ in 48 -h SBP [104], along with decreases in left and right atria dimensions and LV filling pressures [105].

Observational Studies on the Association of Lung USEstimated Volume Overload with Clinical Outcomes in PD Patients

As of this writing, studies using lung US in PD populations are sparse. As shown in Table 5, a cross-sectional study from Italy [106] studied the presence of extravascular lung water, clinical, and BIA parameters in $88 \mathrm{PD}$ patients, of whom 61 underwent echocardiography. Moderate to severe lung congestion, defined as the presence in lung US of a score of B lines between 15 and 30 and $>30$, respectively, was evident in $46 \%$ of patients. No association was found between edema and B lines on univariate and multivariate analyses. In contrast, NYHA class and residual diuresis were found to be associated with the $\mathrm{B}$ lines score $\left(\beta_{0}=0.31, p=0.006\right.$ and $\beta_{0}=0.3, p=0.006$ respectively). In the subset of patients who underwent echocardiography, only LV ejection fraction and left atrial volume were found to be strong and independent predictors of the B-lines score $\left(\beta_{0}=-0.36, p=0.007\right.$ and $\beta_{0}=0.29$, $p=0.05$ respectively), while no association was found with NYHA classification and presence of peripheral edema in multiple regression analysis. Notably, among patients with moderate and severe lung congestion documented with lung US, volume excess was revealed only in 15 and $11 \%$, respectively, with the bioimpendance technique, and the majority of them (60 and 57\%) were classified as NYHA Class I due to the absence of symptoms; these re-

Volume Status Assessment in Peritoneal Dialysis sults exemplify the disagreement between BIA and lung US estimations of volume overload. In a smaller crosssectional study from the UK [107] with 27 PD patients, concordance between BIS measurements, lung US evaluations, and NT-pro-BNP levels was assessed. In contrast to the previous study, the number of patients with lung congestion, defined as a B lines score $>5$ was lower $(14.8 \%)$; there was a statistically significant correlation between the lung score and the NT-pro-BNP values $(r=0.65, p<$ $0.0005)$, but such a correlation was not evident between the B lines score and BIS parameters $(r=0.31, p=0.12)$. The authors concluded that as lung echocardiography and biomarkers detect intravascular and pulmonary volume excess, while BIS methods estimate overall hydration status, thus the methods can be complementary.

\section{Conclusions}

The optimal assessment of volume status in patients undergoing PD is an ongoing clinical problem. The information obtained from patient symptoms and physical examination is often unreliable, and there are currently no data supporting associations between symptoms and physical signs and volume overload assessed with an objective method. Thus, the search for a valid, reproducible, easily applicable, and inexpensive by-the-bed method to assess hydration status is ongoing for several years. Measurement of IVC diameter has been associated with adverse echocardiography indexes in pilot studies in $\mathrm{PD}$ patients, but there are no studies on its associations with mortality and the need for experienced operators and high costs make its wide application in clinical practice rather difficult in many countries. Among natriuretic peptides, only NT-pro-BNP has been associated with mortality in some studies; however, their interpretation is complicated by the presence of cardiac disease, and they are not universally available. BIA techniques are the most studied tool to assess volume overload in PD patients. Volume overload assessed with BIA techniques has been associated with technique failure and increased mortality in a number of studies, but the results of randomized trials on the value of BIA-based strategies to improve volume-related outcomes are largely contradictory. Lung US is a relatively recent technique, with the ability to identify volume excess in a critical area, that is, the lungs; the number of B lines was shown in pilot PD studies to correlate with NT-pro-BNP levels and echocardiographic parameters but not with clinical signs of volume overload and BIA measurements. Overall, current knowledge suggests that 
none of the above methods have so far proved its value as an intervening tool for modifying cardiac parameters, cardiovascular events, technique, and overall survival in $\mathrm{PD}$ patients. As these techniques estimate fluid overload in different compartments of the body, the information provided by combining them could be complementary and more effective in the assessment of volume status. Future research should elucidate whether strategies to assess volume overload using combinations of the above techniques (i.e., BIA and lung US) may prove useful in reduction of volume-related outcomes in PD patients.

\section{Disclosure Statement}

All authors disclose that they do not have any financial or other relationships, which might lead to a conflict of interest regarding this paper.

\section{Funding Sources}

This paper was not supported by any source and represents an original effort of the authors.

\section{References}

1 Sarafidis PA, Persu A, Agarwal R, Burnier M, de Leeuw P, Ferro C, et al. Hypertension in dialysis patients: a consensus document by the European Renal and Cardiovascular Medicine (EURECA-m) working group of the European Renal Association: European Dialysis and Transplant Association (ERA-EDTA) and the Hypertension and the Kidney working group of the European Society of Hypertension (ESH). J Hypertens. 2017;35:657-76.

2 Dekker MJ, Marcelli D, Canaud BJ, Carioni P, Wang Y, Grassmann A, et al. Impact of fluid status and inflammation and their interaction on survival: a study in an international hemodialysis patient cohort. Kidney Int. 2017;91: 1214-23.

3 Konings CJ, Kooman JP, Schonck M, Dammers R, Cheriex E, Palmans Meulemans AP, et al. Fluid status, blood pressure, and cardiovascular abnormalities in patients on peritoneal dialysis. Perit Dial Int. 2002;22:477-87.

4 Kang SH, Choi EW, Park JW, Cho KH, Do JY. Clinical significance of the edema index in incident peritoneal dialysis patients. PLoS One. 2016;11:e0147070.

5 Krediet RT, Balafa O. Cardiovascular risk in the peritoneal dialysis patient. Nat Rev Nephrol. 2010;6:451-60.

6 Wang AY, Brimble KS, Brunier G, Holt SG, Jha V, Johnson DW, et al. ISPD cardiovascular and metabolic guidelines in adult peritoneal dialysis patients part I: assessment and management of various cardiovascular risk factors. Perit Dial Int. 2015;35:379-87.

7 Agarwal R, Andersen MJ, Pratt JH. On the importance of pedal edema in hemodialysis patients. Clin J Am Soc Nephrol. 2008;3:153-8.

8 Ferreira-Filho SR, Machado GR, Ferreira VC, Rodrigues CF, Proenca de Moraes T, DivinoFilho JC, et al. Back to basics: pitting edema and the optimization of hypertension treatment in incident peritoneal dialysis patients (BRAZPD). PLoS One. 2012;7:e36758.

9 Plum J, Schoenicke G, Kleophas W, Kulas W, Steffens F, Azem A, et al. Comparison of body fluid distribution between chronic haemodialysis and peritoneal dialysis patients as assessed by biophysical and biochemical methods. Nephrol Dial Transplant. 2001;16:2378-85.

10 Woodrow G, Oldroyd B, Turney JH, Davies PS, Day JM, Smith MA. Four-component model of body composition in chronic renal failure comprising dual-energy X-ray absorptiometry and measurement of total body water by deuterium oxide dilution. Clin Sci. 1996;91:763-9.

11 Lee SY, Gallagher D. Assessment methods in human body composition. Curr Opin Clin Nutr Metab Care. 2008;11:566-72.

12 Locatelli F, Fouque D, Heimburger O, Drueke TB, Cannata-Andia JB, Horl WH, et al. Nutritional status in dialysis patients: a European consensus. Nephrol Dial Transplant. 2002;17: 563-72.

13 Abrahamsen B, Hansen TB, Hogsberg IM, Pedersen FB, Beck-Nielsen H. Impact of hemodialysis on dual X-ray absorptiometry, bioelectrical impedance measurements, and anthropometry. Am J Clin Nutr. 1996;63:80-6.

14 KDIGO 2017 Clinical Practice Guideline Update for the diagnosis, evaluation, prevention, and treatment of chronic kidney disease-mineral and bone disorder (CKD-MBD). Kidney Int Suppl. 2017;7:1-59.

15 Malluche HH, Porter DS, Pienkowski D. Evaluating bone quality in patients with chronic kidney disease. Nat Rev Nephrol. 2013;9:671-80

16 Kim YL, Biesen WV. Fluid overload in peritoneal dialysis patients. Sem Nephrol. 2017; 37:43-53.

17 Serra-Prat M, Lorenzo I, Palomera E, Yebenes JC, Campins L, Cabre M. Intracellular water content in lean mass is associated with muscle strength, functional capacity, and frailty in community-dwelling elderly individuals. A cross-sectional study. Nutrients. 2019;11:661.

18 Rudski LG, Lai WW, Afilalo J, Hua L, Handschumacher MD, Chandrasekaran K, et al. : Guidelines for the echocardiographic assess- ment of the right heart in adults: a report from the American Society of Echocardiography endorsed by the European Association of Echocardiography, a registered branch of the European Society of Cardiology, and the Canadian Society of Echocardiography. J Am Soc Echocardiogr. 2010;23:685-713;

19 Agarwal R, Bouldin JM, Light RP, Garg A. Inferior vena cava diameter and left atrial diameter measure volume but not dry weight. Clin J Am Soc Nephrol. 2011;6:1066-72.

20 Sakurai T, Ando Y, Masunaga Y, Kusano E, Asano Y. Diameter of the inferior vena cava as an index of dry weight in patients undergoing CAPD. Perit Dial Int. 1996;16:183-5.

21 Oe B, de Fijter CW, Geers TB, Vos PF, Donker AJ, de Vries PM. Diameter of inferior caval vein and impedance analysis for assessment of hydration status in peritoneal dialysis. Artif Organs. 2000;24:575-7.

22 Toprak A, Koc M, Tezcan H, Ozener IC, Akoglu E, Oktay A. Inferior vena cava diameter determines left ventricular geometry in continuous ambulatory peritoneal dialysis patients: an echocardiographic study. Nephrol Dial Transplant. 2003;18:2128-33.

23 Mandelbaum A, Ritz E. Vena cava diameter measurement for estimation of dry weight in haemodialysis patients. Nephrol Dial Transplant. 1996;11(Suppl 2):24-7.

24 Flythe JE, Chang TI, Gallagher MP, Lindley E, Madero M, Sarafidis PA, et al. Blood pressure and volume management in dialysis: conclusions from a Kidney Disease: improving Global Outcomes (KDIGO) Controversies Conference. Kidney Int. 2020 May;97(5):861-76.

25 Wang AY. Clinical utility of natriuretic peptides in dialysis patients. Semin Dial. 2012;25: 326-33.

26 Schaub JA, Coca SG, Moledina DG, Gentry M, Testani JM, Parikh CR. Amino-terminal pro-B-type natriuretic peptide for diagnosis and prognosis in patients with renal dysfunction: a systematic review and meta-analysis. JACC Heart Fail. 2015;3:977-89. 
27 Palmer SC, Yandle TG, Nicholls MG, Frampton CM, Richards AM. Regional clearance of amino-terminal pro-brain natriuretic peptide from human plasma. Eur J Heart Fail. 2009; 11:832-9.

28 DeFilippi C, van Kimmenade RR, Pinto YM. Amino-terminal pro-B-type natriuretic peptide testing in renal disease. Am J Cardiol. 2008; 101:82-8.

29 Zoccali C, Mallamaci F, Benedetto FA, Tripepi G, Parlongo S, Cataliotti A, et al. Cardiac natriuretic peptides are related to left ventricular mass and function and predict mortality in dialysis patients. J Am Soc Nephrol. 2001; 12:1508-15.

30 Akiba T, Tachibana K, Togashi K, Hiroe M, Marumo F. Plasma human brain natriuretic peptide in chronic renal failure. Clin Nephrol. 1995;44(Suppl 1):S61-64.

31 Sivalingam M, Vilar E, Mathavakkannan S, Farrington $\mathrm{K}$. The role of natriuretic peptides in volume assessment and mortality prediction in haemodialysis patients. BMC Nephrol. 2015; 16:218.

32 Wang AY, Lam CW, Yu CM, Wang M, Chan $\mathrm{IH}$, Zhang $\mathrm{Y}$, et al. N-terminal pro-brain natriuretic peptide: an independent risk predictor of cardiovascular congestion, mortality, and adverse cardiovascular outcomes in chronic peritoneal dialysis patients. J Am Soc Nephrol. 2007;18:321-30.

33 Crepaldi C, Rosner M, Teixeira C, Martos LB, Martino FK, Rodighiero MP, et al. Is brain natriuretic peptide a reliable biomarker of hydration status in all peritoneal dialysis patients? Blood Purif. 2014;37:238-42.

34 Davenport A. Changes in N-terminal probrain natriuretic peptide correlate with fluid volume changes assessed by bioimpedance in peritoneal dialysis patients. Am J Nephrol. 2012;36:371-6.

35 Paniagua R, Ventura MD, Avila-Diaz M, Hinojosa-Heredia H, Mendez-Duran A, CuetoManzano A, et al. NT-proBNP, fluid volume overload and dialysis modality are independent predictors of mortality in ESRD patients. Nephrol Dial Transplant. 2010;25:551-7.

36 Paniagua R, Amato D, Mujais S, Vonesh E, Ramos A, Correa-Rotter R, et al. Predictive value of brain natriuretic peptides in patients on peritoneal dialysis: results from the ADEMEX trial. Clin J Am Soc Nephrol. 2008;3:407-15.

37 Oh HJ, Lee MJ, Lee HS, Park JT, Han SH, Yoo $\mathrm{TH}$, et al. NT-proBNP: is it a more significant risk factor for mortality than troponin $\mathrm{T}$ in incident hemodialysis patients? Medicine. 2014;93:e241.

38 Garg R, Singh A, Khaja A, Martin A, Aggarwal $\mathrm{K}$. How does volume status affect BNP and troponin levels as markers of cardiovascular status in peritoneal dialysis? Congest Heart Fail. 2009;15:240-4

39 Jaffrin MY, Morel H: Body fluid volumes measurements by impedance: a review of bioimpedance spectroscopy (BIS) and bioimpedance analysis (BIA) methods. Med Eng Phys. 2008;30:1257-69.
40 Kyle UG, Bosaeus I, De Lorenzo AD, Deurenberg P, Elia M, Gomez JM, et al. Bioelectrical impedance analysis: part I: review of principles and methods. Clin Nutr. 2004;23:1226-43.

41 Morel H, Jaffrin MY. A bridge from bioimpedance spectroscopy to $50 \mathrm{kHz}$ bioimpedance analysis: application to total body water measurements. Physiol Meas. 2008;29:S465-78.

42 Grimnes S, Martinsen O. Bioimpedance and bioelectricity basics. 3rd ed. London, UK: Elsevier Ltd.; 2015. p 1-8.

43 Lukaski HC, Vega Diaz N, Talluri A, Nescolarde L. Classification of hydration in clinical conditions: indirect and direct approaches using bioimpedance. Nutrients. 2019;11:809.

44 Lorenzo AD, Andreoli A. Segmental bioelectrical impedance analysis. Curr Opin Clin Nutr Metab Care. 2003;6:551-5.

45 Davies SJ, Davenport A. The role of bioimpedance and biomarkers in helping to aid clinical decision-making of volume assessments in dialysis patients. Kidney Int. 2014; 86:489-96.

46 Piccoli A, Pastori G, Guizzo M, Rebeschini M, Naso A, Cascone C. Equivalence of information from single versus multiple frequency bioimpedance vector analysis in hemodialysis. Kidney Int. 2005;67:301-13.

47 Moissl UM, Wabel P, Chamney PW, Bosaeus I, Levin NW, Bosy-Westphal A, et al. Body fluid volume determination via body composition spectroscopy in health and disease. Physiol Meas. 2006;27:921-33.

48 Silva AM, Matias CN, Nunes CL, Santos DA, Marini E, Lukaski HC, et al. Lack of agreement of in vivo raw bioimpedance measurements obtained from two single and multifrequency bioelectrical impedance devices. Eur J Clin Nutr. 2019;73:1077-83.

49 Nescolarde L, Lukaski H, De Lorenzo A, deMateo-Silleras B, Redondo-Del-Rio MP, Camina-Martin MA. Different displacement of bioimpedance vector due to $\mathrm{Ag} / \mathrm{AgCl}$ electrode effect. Eur J Clin Nutr. 2016;70:1401-7.

50 Kotanko P, Levin NW, Zhu F. Current state of bioimpedance technologies in dialysis. Nephrol Dial Transplant. 2008;23:808-12.

51 Zhu F, Levin NW. Estimation of body composition and normal fluid status using a calf bioimpedance technique. Blood Purif. 2015;39: 25-31.

52 Liu L, Zhu F, JGR, Thijssen S, Sipahioglu MH, Wystrychowski G, et al. Determination of fluid status in haemodialysis patients with whole body and calf bioimpedance techniques. Nephrology. 2012;17:131-40.

53 Zhu F, Leonard EF, Levin NW. Extracellular fluid redistribution during hemodialysis: bioimpedance measurement and model. Physiol Meas. 2008;29:S491-501.

54 Konings CJ, Kooman JP, Schonck M, CoxReijven PL, van Kreel B, Gladziwa U, et al. Assessment of fluid status in peritoneal dialysis patients. Perit Dial Int. 2002;22:683-92.

$55 \mathrm{Ng} \mathrm{JK}, \mathrm{Li}$ PK. Fluid management and bioimpedance study in peritoneal dialysis.
Curr Opin Nephrol Hypertens. 2019;28:5864.

56 Cheng LT, Tang W, Wang T. Strong association between volume status and nutritional status in peritoneal dialysis patients. Am J Kidney Dis. 2005;45:891-902.

57 Van Biesen W, Williams JD, Covic AC, Fan S, Claes K, Lichodziejewska-Niemierko M, et al. Fluid status in peritoneal dialysis patients: the European Body Composition Monitoring (EuroBCM) study cohort. PLoS One. 2011;6: e17148.

58 Kraemer M, Rode C, Wizemann V. Detection limit of methods to assess fluid status changes in dialysis patients. Kidney Int. 2006;69: 1609-20.

59 Mendley SR, Majkowski NL, Schoeller DA. Validation of estimates of total body water in pediatric dialysis patients by deuterium dilution. Kidney Int. 2005;67:2056-62.

60 Onofriescu M, Siriopol D, Voroneanu L, Hogas S, Nistor I, Apetrii M, et al. Cardiac function and survival in hemodialysis patients. PLoS One. 2015;10:e0135691.

61 Arroyo D, Panizo N, Abad S, Vega A, Rincon A, de Jose AP, et al. Intraperitoneal fluid overestimates hydration status assessment by bioimpedance spectroscopy. Perit Dial Int. 2015; 35:85-9.

62 Davenport A. Effect of intra-abdominal dialysate on bioimpedance-derived fluid volume status and body composition measurements in peritoneal dialysis patients. Perit Dial Int. 2013;33:578-9.

63 Kaysen GA, Yeun J, Depner T. Albumin synthesis, catabolism and distribution in dialysis patients. Miner Electrolyte Metab. 1997;23: $218-24$

64 Chamney PW, Wabel P, Moissl UM, Muller MJ, Bosy-Westphal A, Korth O, et al. A whole-body model to distinguish excess fluid from the hydration of major body tissues. Am J Clin Nutr. 2007;85:80-9.

65 Chan C, McIntyre C, Smith D, Spanel P, Davies SJ. Combining near-subject absolute and relative measures of longitudinal hydration in hemodialysis. Clin J Am Soc Nephrol. 2009;4: 1791-8.

66 John B, Tan BK, Dainty S, Spanel P, Smith D, Davies SJ. Plasma volume, albumin, and fluid status in peritoneal dialysis patients. Clin J Am Soc Nephrol. 2010;5:1463-70.

67 Tan BK, Chan C, Davies SJ. Achieving euvolemia in peritoneal dialysis patients: a surprisingly difficult proposition. Sem Dial. 2010;23:456-61.

68 Wang AY, Dong J, Xu X, Davies S. Volume management as a key dimension of a highquality PD prescription. Peritoneal dialysis international. J Int Soc Perit Dial. 2020; 896860819895365

69 Ronco C, Verger C, Crepaldi C, Pham J, De Los Rios T, Gauly A, et al. Baseline hydration status in incident peritoneal dialysis patients: the initiative of patient outcomes in dialysis (IPOD-PD study). Nephrol Dial Transplant. 2015;30:849-58. 
70 Van Biesen W, Verger C, Heaf J, Vrtovsnik F, Britto ZML, Do JY, et al. Evolution over time of volume status and PD-related practice patterns in an incident peritoneal dialysis cohort. Clin J Am Soc Nephrol. 2019;14:88293.

71 Devolder I, Verleysen A, Vijt D, Vanholder R, Van Biesen W. Body composition, hydration, and related parameters in hemodialysis versus peritoneal dialysis patients. Perit Dial Int. 2010;30:208-14.

72 Wang X, Axelsson J, Lindholm B, Wang T. Volume status and blood pressure in continuous ambulatory peritoneal dialysis patients. Blood Purif. 2005;23:373-8.

73 Law MC, Kwan BC, Fung JS, Chow KM, Ng JKC, Pang WF, et al. The efficacy of managing fluid overload in chronic peritoneal dialysis patients by a structured nurse-led intervention protocol. BMC Nephrol. 2019;20:454.

74 Jones CH, Newstead CG. The ratio of extracellular fluid to total body water and technique survival in peritoneal dialysis patients. Perit Dial Int. 2004;24:353-8.

75 O’Lone EL, Visser A, Finney H, Fan SL. Clinical significance of multi-frequency bioimpedance spectroscopy in peritoneal dialysis patients: independent predictor of patient survival. Nephrol Dial Transplant. 2014;29: 1430-7.

76 Guo Q, Lin J, Li J, Yi C, Mao H, Yang X, et al. The effect of fluid overload on clinical outcome in southern Chinese patients undergoing continuous ambulatory peritoneal dialysis. Perit Dial Int. 2015;35:691-702.

77 Rhee H, Baek MJ, Chung HC, Park JM, Jung WJ, Park SM, et al. Extracellular volume expansion and the preservation of residual renal function in Korean peritoneal dialysis patients: a long-term follow up study. Clin Exp Nephrol. 2016;20:778-86.

78 Fan S, Davenport A. The importance of overhydration in determining peritoneal dialysis technique failure and patient survival in anuric patients. Int J Artif Organs. 2015;38:5759.

79 Chen W, Guo LJ, Wang T. Extracellular water/intracellular water is a strong predictor of patient survival in incident peritoneal dialysis patients. Blood Purif. 2007;25:260-6.

80 Oei E, Paudel K, Visser A, Finney H, Fan SL. Is overhydration in peritoneal dialysis patients associated with cardiac mortality that might be reversible? World J Nephrol. 2016;5: $448-54$.

81 Jotterand Drepper V, Kihm LP, Kalble F, Diekmann C, Seckinger J, Sommerer C, et al. Overhydration is a strong predictor of mortality in peritoneal dialysis patients: independently of cardiac failure. PLoS One. 2016;11: e0158741.

82 Fein P, Chattopadhyay J, Paluch MM, Borawski C, Matza B, Avram MM. Enrollment fluid status is independently associated with long-term survival of peritoneal dialysis patients. Adv Perit Dial Conf Perit Dial. 2008;24: $79-83$.
83 Kim JK, Song YR, Lee HS, Kim HJ, Kim SG. Repeated bioimpedance measurements predict prognosis of peritoneal dialysis patients. Am J Nephrol. 2018;47:120-9.

84 Shu Y, Liu J, Zeng X, Hong HG, Li Y, Zhong $\mathrm{H}$, et al. The effect of overhydration on mortality and technique failure among peritoneal dialysis patients: a systematic review and meta-analysis. Blood Purif. 2018;46:350-8.

85 McCafferty K, Fan S, Davenport A. Extracellular volume expansion, measured by multifrequency bioimpedance, does not help preserve residual renal function in peritoneal dialysis patients. Kidney Int. 2014;85:151-7.

86 Luo YJ, Lu XH, Woods F, Wang T. Volume control in peritoneal dialysis patients guided by bioimpedance spectroscopy assessment. Blood Purif. 2011;31:296-302.

87 Hong YA, Yoon HE, Choi BS, Shin SJ, Kim YS, Lee SY, et al. the effect of strict volume control assessed by repeated bioimpedance spectroscopy on cardiac function in peritoneal dialysis patients. Sci Rep. 2019;9:17679.

88 Oh KH, Baek SH, Joo KW, Kim DK, Kim YS, Kim S, et al. Does routine bioimpedanceguided fluid management provide additional benefit to non-anuric peritoneal dialysis patients? Results from COMPASS clinical trial. Peritoneal dialysis international. J Int Soc Perit Dial. 2018;38:131-8.

89 Yoon HE, Kwon YJ, Shin SJ, Lee SY, Lee S, Kim SH, et al. Bioimpedance spectroscopyguided fluid management in peritoneal dialysis patients with residual kidney function: a randomized controlled trial. Nephrology. 2019;24:1279-89.

90 Tan BK, Yu Z, Fang W, Lin A, Ni Z, Qian J, et al. Longitudinal bioimpedance vector plots add little value to fluid management of peritoneal dialysis patients. Kidney Int. 2016 Feb; 89(2):487-97.

91 Hur E, Usta M, Toz H, Asci G, Wabel P, Kahvecioglu $S$, et al. Effect of fluid management guided by bioimpedance spectroscopy on cardiovascular parameters in hemodialysis patients: a randomized controlled trial. Am J Kidney Dis. 2013;61:957-65.

92 Onofriescu M, Hogas S, Voroneanu L, Apetrii M, Nistor I, Kanbay M, et al. Bioimpedanceguided fluid management in maintenance hemodialysis: a pilot randomized controlled trial. Am J Kidney Dis. 2014;64:111-8.

93 Covic A, Ciumanghel AI, Siriopol D, Kanbay M, Dumea R, Gavrilovici C, et al. Value of bioimpedance analysis estimated "dry weight" in maintenance dialysis patients: a systematic review and meta-analysis. Int Urol Nephrol. 2017;49:2231-45.

94 Zoccali C. lung ultrasound in the management of fluid volume in dialysis patients: potential usefulness. Semin Dial. 2017;30:6-9.

95 Picano E, Frassi F, Agricola E, Gligorova S, Gargani L, Mottola G. Ultrasound lung comets: a clinically useful sign of extravascular lung water. J Am Soc Echocardiogr. 2006;19: 356-63.
96 Gargani L, Frassi F, Soldati G, Tesorio P, Gheorghiade M, Picano E. Ultrasound lung comets for the differential diagnosis of acute cardiogenic dyspnoea: a comparison with natriuretic peptides. Eur J Heart Fail. 2008; 10:70-7.

97 Zoccali C, Puntorieri E, Mallamaci F. Lung congestion as a hidden threat in end-stage kidney disease: a call to action. Nephrol Dial Transplant. 2013;28:2657-60.

98 Covic A, Siriopol D, Voroneanu L. Use of lung ultrasound for the assessment of volume status in CKD. Am J Kidney Dis. 2018; 71:412-22.

99 Mallamaci F, Benedetto FA, Tripepi R, Rastelli S, Castellino P, Tripepi G, et al. Detection of pulmonary congestion by chest ultrasound in dialysis patients. JACC Cardiovas Imag. 2010;3:586-94.

100 Torino C, Gargani L, Sicari R, Letachowicz $\mathrm{K}$, Ekart R, Fliser D, et al. The agreement between auscultation and lung ultrasound in hemodialysis patients: the LUST study. Clin J Am Soc Nephrol. 2016;11:2005-11.

101 Siriopol D, Voroneanu L, Hogas S, Apetrii M, Gramaticu A, Dumea R, et al. Bioimpedance analysis versus lung ultrasonography for optimal risk prediction in hemodialysis patients. Int J Cardiovas Imag. 2016;32:26370.

102 Donadio C, Bozzoli L, Colombini E, Pisanu G, Ricchiuti G, Picano E, et al. Effective and timely evaluation of pulmonary congestion: qualitative comparison between lung ultrasound and thoracic bioelectrical impedance in maintenance hemodialysis patients. Medicine. 2015;94:e473.

103 Zoccali C, Torino C, Tripepi R, Tripepi G, D’Arrigo G, Postorino M, et al. Pulmonary congestion predicts cardiac events and mortality in ESRD. J Am Soc Nephrol. 2013;24: 639-46.

104 Loutradis C, Sarafidis PA, Ekart R, Papadopoulos $\mathrm{C}$, Sachpekidis V, Alexandrou ME, et al. The effect of dry-weight reduction guided by lung ultrasound on ambulatory blood pressure in hemodialysis patients: a randomized controlled trial. Kidney Int. 2019; 95:1505-13.

105 Loutradis C, Papadopoulos CE, Sachpekidis V, Ekart R, Krunic B, Karpetas A, et al. Lung ultrasound-guided dry weight assessment and echocardiographic measures in hypertensive hemodialysis patients: a randomized controlled study. Am J kidney Dis. 2020;75: 11-20.

106 Panuccio V, Enia G, Tripepi R, Torino C, Garozzo M, Battaglia GG, et al. Chest ultrasound and hidden lung congestion in peritoneal dialysis patients. Nephrol Dial Transplant. 2012;27:3601-5.

107 Paudel K, Kausik T, Visser A, Ramballi C, Fan SL. Comparing lung ultrasound with bioimpedance spectroscopy for evaluating hydration in peritoneal dialysis patients. $\mathrm{Ne}-$ phrology. 2015;20:1-5. 